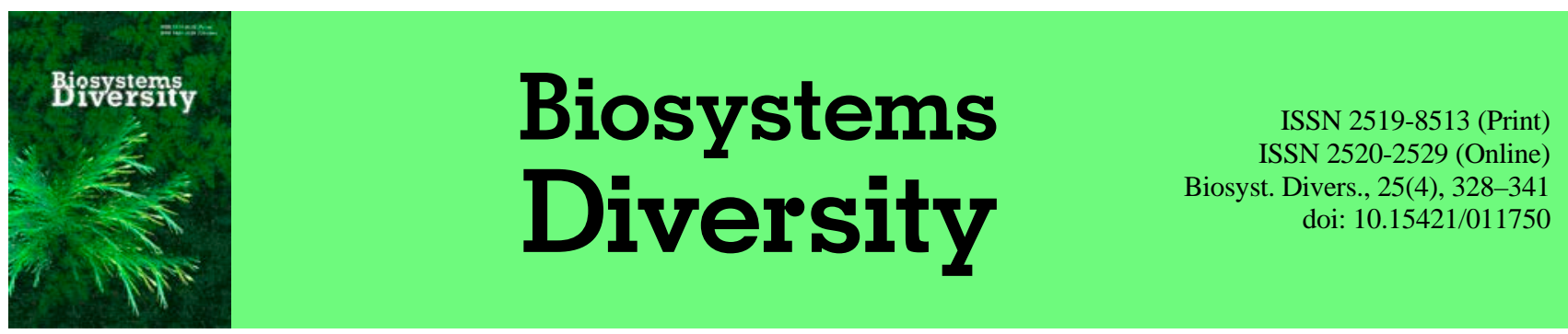

\title{
Sensitivity and resistance of communities: Evaluation on the example of the influence of edaphic, vegetation and spatial factors on soil macrofauna
}

\author{
O. V. Zhukov*, O. M. Kunah*, Y. Y. Dubinina** \\ *Oles Honchar Dnipro National University, Dnipro, Ukraine \\ **Melitopol Institute of Ecology and Social Technologies \\ of the Open International University of Human Development "Ukraine", Melitopol, Ukraine
}

\section{Article info}

Received 20.10.2017

Received in revised form 14.11.2017

Accepted 16.11.2017

Oles Honchar Dnipro National University, Kazakova st., 17,

Dnipro, 49010, Ukraine. Tel.: +38-098-858-23-79.

E-mail: zhukov_dnipro@ukr.net

Melitopol Institute of Ecology and Social Technologies of the Open International University of Human

Development "Ukraine",

Interculturnaya st., 380,

Melitopol, 72316, Ukraine.
Zhukov, O. V., Kunah, O. M., \& Dubinina, Y. Y. (2017). Sensitivity and resistance of communities: Evaluation on the example of the influence of edaphic, vegetation and spatial factors on soil macrofauna. Biosystems Diversity, 25(4), 328-341. doi:10.15421/011750

Environmental stability is a multifaceted concept and includes properties such as asymptotic stability, robustness, persistence, variability, elasticity and resistance. Resistance reflects the ability of a community or population to remain in a substantially unaltered state under external influence. The reverse of resistance is sensitivity. This article suggests a way to assess the sensitivity of animal communities to factors of various character and explain sensitivity and resistance of the macrofauna community near the floodplain of the river Dnieper within the "Dnipro-Orelsky" Nature Reserve to the effects of edaphic and plant factors, as well as spatial variables. It is shown that the regulatory impact of environmental factors is refracted through the properties of ecological systems themselves, namely resistance and sensitivity. If an ecological system does not react to changing environmental factors, such a system is indifferent with respect to these factors. In the case of regulatory influence of factors, there may be resistance, sensitivity and the proportionality of the response of the ecological system. The ratio of the specific role of a factor in the variability of a community to the contribution of the main components of the total variability of the attributive space makes it possible to assess the resistance, sensitivity and proportionality of response the ecological system to the action of that factor. If the ratio is $>1$, then this indicates sensitivity: level of variability of a community is higher than the relative role of environmental factors in the changing of the attributive space. If $<1$, this indicates resistance: the level of variability of a community is lower than the relative role of environmental factors in the changing of the attributive space. If the ratio $=1(\approx 1)$, changes in the community are proportional to the level of the main components of variation in comparison with other components. Ecological factors (both external environmental and internal due to species interactions and which have a neutral nature) cause different levels of community response to their impact. These differences refracted through different aspects of stability of a community can be described using the categories resistance, sensitivity and proportionality. The proposed procedure for quantification of specified properties of sustainability has established that the floodplain soil macrofauna is endowed with resistance to factors that prevail on the level of its variation. However, macrofauna is highly sensitive to minor factors. The community of the soil inhabitants is sensitive to fine-scale variations, which have a neutral nature.

\section{Сенситивность и резистентность сообществ: оценка на примере влияния эдафических, растительных и пространственных факторов на почвенную макрофауну}

\author{
А. В. Жуков*, О. Н. Кунах*, Ю. Ю. Дубинина** \\ *Днипровский национальный университет имени Олеся Гончара, Днипро, Украина \\ **Мелитопольский институт экологии и социальных технологий Открытого международного университета \\ гуманитарного развития «Украина», Мелитополь, Украина
}

Экологическая устойчивость является многоплановой концепцией и включает такие свойства как асимптотическая устойчивость, робастность, персистентность, вариабельность, эластичность и резистентность. Резистентность отражает способность сообщества или популяции оставаться в существенно неизменном состоянии под внешним воздействием. Обратным резистентности является свойство сенситивности. В статье предложен способ оценки сенситивности сообществ животных к факторам различной природы и выяснена сенситивность и резистентность сообщества мезопедобионтов прирусловой поймы р. Днепр в пределах природного заповедника «Днепровско-Орельский» к действию эдафических и растительных факторов, а также пространственных переменных. Регуляторное воздействие экологических факторов преломляется через свойства самих экологических систем, а именно резистентность и сенситивность. 
В случае если экологическая система никак не реагирует на изменение экологических факторов, такая система является индифферентной по отношению к указанным факторам. В случае наличия регулирующего влияния факторов может иметь место резистентность, сенситивность и пропорциональность реакции экологической системы. Отношение удельной роли фактора в вариабельности сообщества к вкладу главной компоненты в суммарную вариабельность признакового пространства позволит оценить резистентность, сенситивность и пропорциональность реакции экологической системы на действие фактора. Если это отношение $>1$, речь идет о сенситивности: уровень вариабельности сообщества выше, чем относительная роль экологического фактора в варьировании признакового пространства. Если < 1 речь идет о резистентности: уровень вариабельности сообщества ниже, чем относительная роль экологического фактора в варьировании признакового пространства. Если отношение $=1(\approx 1)-$ изменения в сообществе пропорциональны уровню варьирования главной компоненты по сравнению с другими компонентами. Экологические факторы (как внешние, средовые, так и внутренние, обусловленные межвидовыми взаимодействиями и имеющими нейтральную природу) вызывают различный уровень реагирования сообщества на свое воздействие. Эти различия преломляются через различные аспекты устойчивости сообщества и могут быть описаны с помощью таких категорий как резистентность, сенситивность и пропорциональность. Предложенная процедура количественной оценки указанных свойств устойчивости позволила установить, что макрофауна пойменной почвы обладает резистентностью к факторам среды, которые превалируют по уровню своего варьирования, тогда как к минорным факторам макрофауна высоко сенситивна. Также сообество обитателей почвы характеризуется сенситивностью к детальномасштабному варьированию, которое имеет нейтральную природу.

Ключевые слова: устойчивость; экологические факторы; теория ниши; нейтральное разнообразие; пространственная экология; индикаторные значения; PCNM-анализ

\section{Введение}

Характер реакции экологических систем в ответ на внешние воздействия - важный аспект изучения экологической устойчивости (Grimm et al., 1992). Экологическая устойчивость многоплановая концепция, она включает такие динамические свойства экосистем как асимптотическая устойчивость, робастность, персистентность, вариабельность, эластичность и резистентность (Pimm, 1984; Ives, 1995; Ives et al., 1999; Donohue et al., 2013). Резистентность отражает способность сообщества или популяции оставаться в существенно неизменном состоянии под внешним воздействием (Grimm and Wissel, 1997). Обратным к резистентности свойством является сенситивность (Burdon et al., 2016). Сенситивное сообщество демонстрирует значительные структурные изменения под внешними воздействиями, что большей частью приводит к снижению биоразнообразия (Grimm et al., 1992). Наблюдаемые изменения в сообществе также могут зависеть от различных свойств воздействия, таких как величина, интенсивность и длительность (Pimm, 1984).

Пространственное варьирование почвенных ресурсов - фактор структурирования сообществ почвенных животных (Drake, 1990; Decaëns et al., 2009; Jiménez et al., 2012; Blanchet et al., 2013). Конкурирующие виды в многовидовых сообществах почвенных экосистем сосуществуют в силу пространственной гетерогенности почвы как среды обитания (Amarasekare, 2003; Jiménez et al., 2012). Сообщества почвенных животных демонстрируют пространственную организацию, которая проявляет себя от пространств отдельных агрегатов (Ettema and Yeates, 2003) зон влияния отдельных растений (Rossi et al., 1996), аграрных полей или природных экосистем (Decaëns and Rossi, 2001; Rossi, 2003; Whalen, 2004). Виды почвенных животных характеризуются специфичной степенью пространственной агрегированости (McArdle and Anderson, 2004). Пространственный масштаб влияния факторов нейтральной природы может быть совершенно различен для разных видов педобионтов (Anderson et al., 2011). Оценка взаимосвязи свойств среды и сообществ дождевых червей с учетом многомасштабного взаимодействия показала, что отношения между пространственной организацией сообщества и почвенными свойствами демонстрируют многоуровневый характер (Jiménez et al., 2014).

Видовое разнообразие и структура сообществ демонстрируют вариабельность в географическом и экологическом пространстве (Lawton, 1999; Hubbell, 2001; Brygadyrenko, 2015). Географическое пространство иерархически организованно, что предполагает существование масштабных уровней пространственной изменчивости параметров экосистем (Legendre, 1993). Экологические процессы на различных пространственных масштабных уровнях влияют на структуру сообществ (Brygadyrenko, 2016; Zhukov et al., 2013). Концепция бета-разнообразия играет ключевую роль в понимании и количественной характеристике организации разнообразия на различных иерархических уровнях (Soinenen et al. 2007). Бета-разнообразие рас- сматривается как изменчивость видового состава сообщества от места к месту и, таким образом, предполагает пространственный контекст (Whittaker, 1960, 1972; Legendre et al., 2005). Пространственным варьированием бета-разнообразия управляют детерминистские или стохастические механизмы (Barot and Gignoux, 2004; Laliberte et al., 2009). Оценка роли каждого из указанных механизмов позволяет экспериментально проверить, какая из теорий является справедливой: экологической ниши или нейтрального разнообразия (Hutchinson, 1957; Hubbell, 2001; Adler et al., 2007; Clark, 2012).

Теория экологической ниши прогнозирует, что чем ближе в географическом пространстве находятся два локальных сообщества, то тем более подобные условия окружающей среды влияют на них. Именно так теория экологической ниши объясняет наблюдаемую пространственную автокорреляцию организации сообщества. Теория нейтральности также предсказывает, что с увеличением географической дистанции различия между сообществами будут также увеличиваться. Такой прогноз указывает, что механизмы формирования пространственной автокорреляции вполне могут иметь и нейтральную природу (Caruso et al., 2012). Ключевая особенность нейтральной динамики состоит в том, что она определяет пространственные паттерны независимо от варьирования свойств и режимов экологического окружения (Hubbell, 2001; Chave, 2004; Dornelas et al., 2006).

Роль нейтральных механизмов может быть оценена с помощью таких предикторов как параметры окружающей среды и пространственные переменные, полученные на основе географических координат мест расположения сообществ. Среди этих предикторов важно установить индивидуальные и комбинированные компоненты, а затем оценить, как эти переменные связанны с вариабельностью и разнообразием сообщества (Murphy et al., 2015). Такая процедура может быть осуществлена с помощью статистического подхода - фракционирования вариации (Borcard et al., 1992; Legendre et al., 2009).

Пространственную автокорреляцию, которая не зависит от экологических факторов, объясняют результатом действия нейтральных механизмов структурированая сообества (Legendre et al., 2009; Hu et al., 2013). К числу нейтральных механизмов относят ограничение пространственной дисперсии индивидов (Siefert et al., 2013). Однако нейтральный аспект варьирования структуры сообщества не может быть отделен от неизмеренных пространственно структурированных переменных. Поэтому пространственную вариацию нельзя полностью отождествлять с результатами нейтрального структурирования сообщества (Anderson et al., 2011). Вариация, которая обусловлена только переменными окружающей среды, может в действительности формировать паттерны, являющиеся следствием нейтральных механизмов (Murphy et al., 2015).

Наблюдаемая пространственная организация сообществ возникает под действием факторов окружающей среды, а также зависит от биологических и исторических причин (Dray 
et al., 2006). Действие этих факторов является взаимодополняющим (Jiménez et al., 2014). Пространственная структура комплексов видов возникает как результат действия, по меньшей мере, одного из структурирующих факторов. В соответствии с теорией экологической ниши, ими могут быть пространственно распределенные факторы среды (Hutchinson, 1957, 1965). На некоторых иерархических уровнях пространственной организации важную структурирующую роль играют межвидовые взаимодействия (Schoener, 1974; Wilson and Habiba, 1995; Belyea and Lancaster, 1999; Zhukov and Gubanova, 2015). Два противоположных типа динамики могут возникнуть в результате межвидовых взаимодействий: детерминистически или исторически обусловленные (Chase, 2003). В соответствии с теорией нейтральности существенное влияние на структуру сообщества оказывают исторические обстоятельства (Ellwood et al., 2009) или стохастические вариации в истории появления видов (Drake, 1990; Weslien et al., 2011). Однако неповторимость и специфичность исторических эффектов делает крайне трудным предсказания динамики экосистемных функций (Fukami et al., 2010). Несмотря на то, что исторические процессы и история перемещения видов не наблюдаемы в режиме реального времени, важно оценить вклады различных источников в вариабельность структуры сообществ (Fukami, 2010; Jiménez et al., 2014). Исследование пространственных масштабов, при которых имеет значение история формирования комплексов живых организмов, может помочь в решении этой важной задачи. Высказано предположение, что экологический и стохастический аспекты гетерогенности проявляют себя на различных масштабных уровнях. При структурировании комплексов на широком масштабном уровне в наибольшей степени должна проявлять себя экологическая гетерогенность. Стохастические процессы, такие как дисперсия, должны преимущественно действовать на детальномасштабных уровнях (Legendre, 1993; Laliberte et al., 2009; Gazol and Ibanez, 2010).

Детерминистский подход делает акцент на том, что условия окружающей среды определяют, какие виды из регионального «пула» смогут сформировать сообщество в результате видовых взаимодействий. Такая точка зрения позволяет сделать прогноз о том, что история иммиграции не влияет на итоговый состав видов сообщества. Верно обратное: если сообщество исторически обусловлено, то единственное климаксовое сообщество не может зависеть только от условий среды (Fukami, 2010). Особое значение имеют размер и уровень изоляции пятен, где сообщество представлено, их пространственная гетерогенность. Роль для сообщества этих характеристик зависит от пространственного масштаба и способности видов к перемещению (Cadotte and Fukami, 2005).

Методы геостатистики широко применяются для характеристики и количественного описания пространственного распределения свойств среды и изменчивости размещения почвенных организмов (Rossi et al., 1996; Rossi et al., 2003). Однако геостатистика не может решить вопрос моделирования пространственных структур на различных масштабных уровнях. Для этого необходимы другие статистические инструменты. Анализ главных координат матриц соседства (Dray et al., 2006; Borcard and Legendre, 1994; Borcard et al., 2004) позволяет связать на различных пространственных уровнях варьирование свойств среды со структурой сообщества (Rossi et al., 1996; Borcard and Legendre, 1994).

Важной проблемой является вопрос о природе экологических градиентов в почве как среде обитания живых организмов. Наряду с рельефом как фактором перераспределения климатических ресурсов факторы фитогенной и зоогенной природы выступают как источники неоднородности свойств почвы (Karpachevsky, 2005). Влияние мезорельефа проявляется на крупномасштабном уровне, а фитогенные и зоогенные эффекты проявляются на крупномасштабном, так и на детальномасштабном и среднемасштабном уровнях (Zhukov et al., 2013). В свою очередь, пространственные паттерны растительности или педотурбационной активности животных могут иметь нейтральную природу. Нельзя исключать того, что факторы гетерогенности экологических свойств почвы в своей основе генерированы нейтральными причинами. Поэтому мы считаем актуальной проблемой оценку соотношения пространственных факторов, а также факторов эдафической и растительной природы в организации сообщества почвенной мезофауны.

Эмпирические исследования устойчивости сообществ обычно фокусируются на измерении пространственной или временной вариабельности некоторых интегративных свойств популяций или сообществ (Zhukov, 2005). Обычно это коэффициент вариации биомассы или численности (Steiner et al., 2005; Tilman, et al., 2006).

Цель настоящего исследования - предложить способ оценки сенситивности сообществ животных к факторам различной природы, выяснить сенситивность и резистентность сообщества мезопедобионтов прирусловой поймы р. Днепр в пределах природного заповедника «Днепровско-Орельский» к действию эдафических и растительных факторов, а также пространственных переменных.

\section{Материал и методы исследований}

Исследования проведены в мае 2017 г. в природном заповеднике «Днепровско-Орельский». Исследуемый полигон заложен на участке, который находится в прирусловой пойме p. Днепр (48²9’24" N, 3446’37" E). Тип биотопа - пойменный дубовый лес (EUNIS - G1.225 Sarmatic riverine [Quercus] forests, CORINE - 44.42 Residual medio-European fluvial forests, Pal. Hab. - 44.45 Sarmatic riverine oak forests, Natura 2000 - 91F0 Riparian mixed forests of Quercus robur, Ulmus leavis and $U$. minor, Fraxinus excelsior or $F$. anguistifolia, along the great rivers Ulmenion minoris) (Didukh et al., 2011).

Полигон состоит из 7 трансект. Каждая трансекта составлена 15 пробными точками (рис. 1).

Расстояние между рядами в полигоне составляет 3 м. В каждой точке сделаны почвенно-зоологические пробы размером 0,25 × 0,25 м для количественного учета почвенной мезофауны. Тип почвы - аллювиальная дерновая лесная слоистая нормальная. Уровень грунтовых вод - из глубины 117 см. Поверхность почвы интенсивно перерыта кабаном.

В пределах каждого квадрата размером $3 \times 3$ м проведено геоботаническое описание растительности. Тип леса по Belgard $(1950,1971)$ - мезофильный свежий вязо-дубняк с будрой De” 2. На основании геоботанических описаний выполнено фитоиндикационное оценивание экологических факторов по Belgard (1950, 1971), Diduh (2011, 2012) и Ellenberg (1974). Экоморфы растений приведены по Belgard $(1950,1971)$ и Tarasov (2012). Гигроморфы представлены ксерофитами (уровень влажности 1), мезоксерофитами (уровень влажности 2), ксеромезофитами (уровень влажности 3), мезофитами (уровень влажности 4), гигромезофитами (уровень влажности 5). Уровень влажности по гигроморфической структуре (Hygr) оценен как:

$$
\text { Hygr }=\frac{\sum_{i=1}^{i=N}\left(i \times P_{i}\right)}{100},
$$

где $i$ - уровень влажности, $P_{i}$ - проективное покрытие растений соответствующей гигроморфы (Zhukov and Zadorozhnaya, 2016).

Трофоморфы представлены олиготрофами (уровень трофности 1), мезотрофами (уровень трофности 2) и мегатрофами (уровень трофности 3). Уровень трофности по трофоморфической структуре (Troph_B) оценен как:

$$
\operatorname{Troph}_{B}=\frac{\sum_{j=1}^{j=N}\left(j \times P_{j}\right)}{100},
$$

где $j$ - уровень трофности, $P_{j}$ - проективное покрытие растений соответствующей трофоморфы.

Гелиоморфы представлены гелиосциофитами (уровень освещения 2), сциогелиофитами (уровень освещения 3), гелиофитами (уровень освещения 4). Уровень освещения по геолиоморфической структуре (Hel) оценен как: 


$$
H e l=\frac{\sum_{z=1}^{z=N}\left(z \times P_{z}\right)}{100}
$$

где $z$ - уровень освещения, $P_{z}$ - проективное покрытие растений соответствующей гелиоморфы.

Фитоиндикационные шкалы по Diduh $(2011,2012)$ включают эдафические и климатические шкалы. К эдафическим фитоиндикационным шкалам относятся показатели гидроморф (Hd, за основу взята шкала Цыганова, 23 градации), переменности увлажнения (fH, 11 градаций), аэрации (Ае, 15 града- ций), режима кислотности (Rc, 15 градаций), солевого режима (Sl, 19 градаций), содержания карбонатных солей (Сa, 13 градаций), содержания усвояемых форм азота (Nt, за основу взята шкала Цыганова, 11 градаций). К климатическим шкалам относят показатели терморежима - масштаб радиационного баланса (Тm, 17 градаций), омброрежима - аридность-гумидность климата (Om, 23 градации), криорежима (Cr, 15 градаций) и континентальности климата (Kn, 17 градаций).

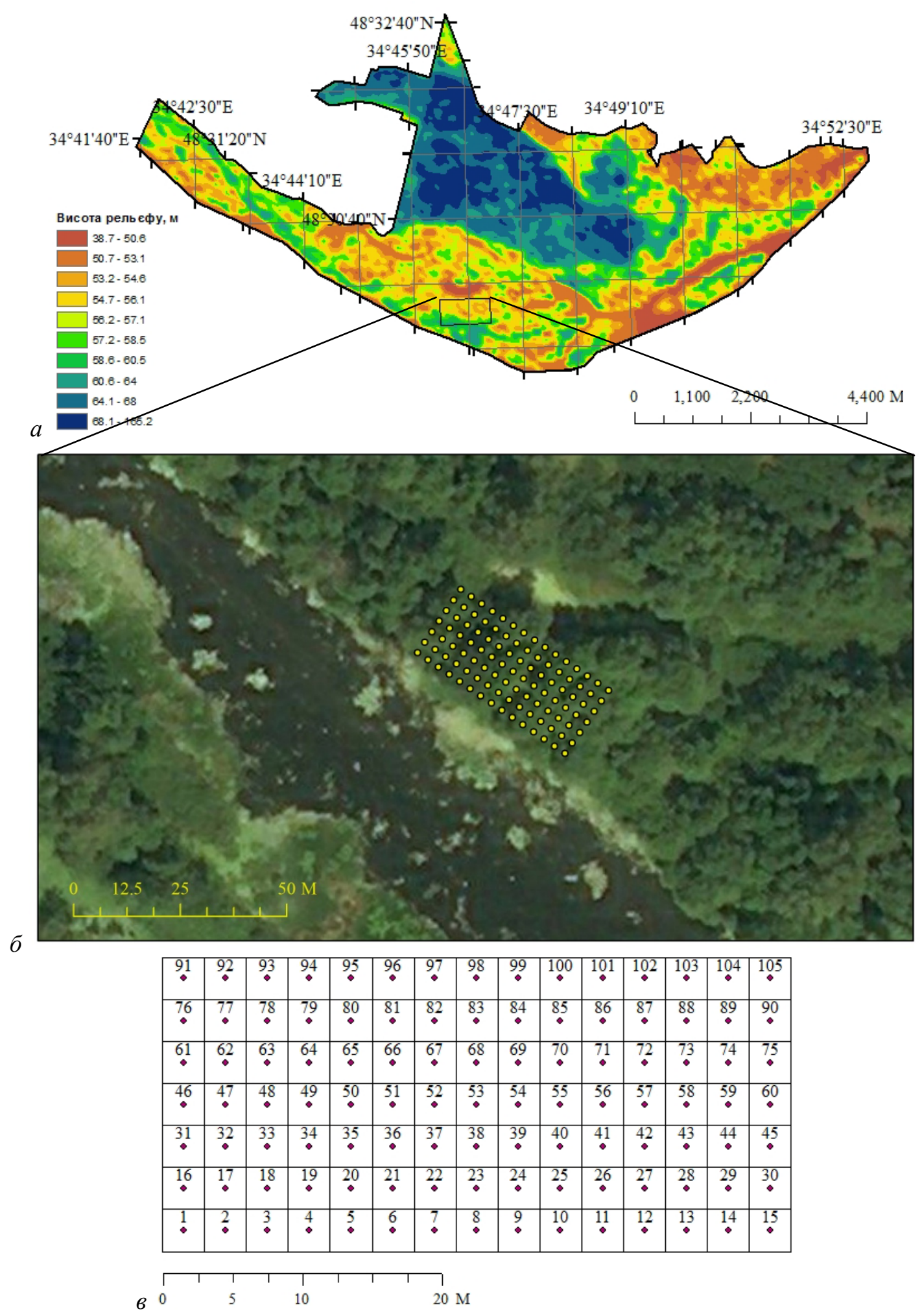

Рис. 1. Схема размещения полигона на территории природного заповедника «Днепровско-Орельский» и пробных точек в нем: $a$ - контур заповедника, представлена цифровая модель рельефа; $\sigma$ - космический снимок изучаемого ландшафта и размещение полигона; в - схема полигона 
Помимо указанных, выделяется еще шкала освещения (Lc, 9 градаций), которую характеризуют как микроклиматическую шкалу. Шкала освещения создана на основе L-шкалы Элленберга. Тепловые свойства почв индицируются шкалой терморежима, а гидротермические - шкалой омброрежима. Фитоиндикационное оценивание экологических факторов выполнено методом идеального индикатора (Buzuk and Sozinov, 2009).

Фитоиндикационные шкалы Ellenberg (1974) включают: L-шкалу освещенности / затенения (9 классов, Light Regime), T-шкалу термоклимата (9 классов, Temperatures), K-шкалу континентальности климата (9 классов, Continentality of Climate), F-шкалу увлажнения почв (12 классов, Humidity), R-шкалу реакции (кислотности) почв или воды (9 классов, Acidity) и N-шкалу богатства почв азотом (9 классов, Nutrients Availability). Оценивали значения экологических факторов производили методом средних взвешенных значений индикаторных шкал с учетом проективного покрытия растений.

Измеряли твердость почв производили в полевых условиях с помощью ручного пенетрометра Eijkelkamp на глубину до 100 cм с интервалом 5 см. Средняя погрешность результатов измерений прибора составляет $\pm 8 \%$. Измерения проводили конусом, поперечным сечением $2 \mathrm{~cm}^{2}$. В пределах каждой точки измерения твердости почвы проводили в однократной повторности.

Для измерения электропроводности почвы in situ использовали сенсор HI 76305 (Hanna Instruments, Woodsocket, R. I.). Этот сенсор работает совместно с портативным прибором HI 993310. Тестер оценивает общую электропроводность почвы, то есть объединенную проводимость почвенного воздуха, воды и частиц. Результаты измерений прибора представлены в единицах насыщенности почвенного раствора солями (г/л). Сравнение результатов измерений прибором НІ 76305 с данными лабораторных исследований позволило оценить коэффициент перевода единиц: 1 дС/м = 155 мг/л (Pennisi and van Iersel, 2002).

Почвенную температуру измеряли с 13 до 14 часов цифровыми термометрами WT-1 (ПАО «Стеклоприбор», http://bit. steklopribor.com, точность $\left.-0,1^{\circ} \mathrm{C}\right)$ на глубине 5-7 см. Измеряли в трехкратной повторности в каждой пробной точке.

Агрегатную структуру оценивали методом сухого просеивания по Савинову. Установлено процентное содержание таких фракций: $<0,25,0,25-0,50,0,5-1,0,1-2,2-3,3-5,5-7,7-$ $10,>10$ мм и корни растений. Плотность почвы оценили по Качинскому, влажность почвы - весовым методом (Vadunina and Korchagina, 1986).

Для снижения размерности признакового пространства и предотвращения мультиколлинеарности предикторов результаты измерения свойств среды подвергли анализу главных компонент. Анализ главных компонент выполнен отдельно для эдафических свойств и для фитоиндикационных показателей. Сформировано две совокупности предикторов свойств среды: эдафические и растительные.

Матрицу численностей видов почвенных животных стандартизировали с использованием дистанции Хеллинджера перед анализом. Далее удалили линейный тренд сообщества мезопедобионтов. Пространственная структура может быть моделирована с помощью множества независимых пространственных паттернов - главных координат матрицы близости (PCNM - Principal coordinates of neighbor matrices, или более позднее название MEMs - Moran's eigenvector maps). Пространственные переменные вычислены после спектральной декомпозиции усеченной матрицы расстояний между точками отбора проб. Порядок этих переменных соответствует последовательности вариации от крупномасштабной к средне- и детальномасштабной. PCNM-подход позволяет получить $n-1$ пространственную переменную с позитивными и негативными собственными числами. Для анализа отобраны в качестве предикторов переменные только с позитивными собственными числами. Прямой выбор переменных среды или пространственных переменных выполнен с помощью функции forward.sel в пакете Packfor (доступен по адресу www.bio.umontreal.ca/legendre).
Процедура прямого выбора позволяет отобрать переменные со значимым (Р < 0,05 после 999 пермутаций) вкладом в объясненную вариацию сообщества почвенных животных (Blanchet et al., 2008). Только отобранные переменные использовали для дальнейшего анализа.

Фракционирование вариации (Borcard et al., 1992) выполнено для количественной оценки пропорций вариации композиции сообщества, которые объясняются совокупностью переменных среды или пространственных переменных. Откорректированные значения $\mathrm{R}^{2}$ позволили вычислить чистую компоненту окружающей среды, чистую пространственную компоненту и смешанную пространственную и средовую компоненты варьирования сообщества.

Анализ избыточности (redundancy analysis - CA) и линейный регрессионный анализ использовали для того, чтобы выяснить характер зависимости пространственно структурированного варьирования сообщества мезопедобионтов от эдафических и растительных факторов среды на крупномасштабном, среднемасштабном и детальномасштабном пространственных уровнях.

Статистические расчеты проведены с помощью програмной оболочки Project R "R: A Language and Environment for Statistical Computing" (www.R-project.org). Оценивание доверительных интервалов и стандартного отклонения численности почвенных животных проведено с помощью бутстреп-подхода и выполнено средствами пакета bootES (Kirby and Gerlanc, 2013).

\section{Результаты и обсуждение}

Оценка сенситивности и резистентности сообщества к действию экологических факторов. Экологические факторы делятся на две категории: определяющие и регулирующие (Odum, 1953). Определяющие факторы являются константными и создают общий контекст существования экологических систем. Кислород в атмосфере - важный экологический фактор, но на уровне поверхности Земли концентрация кислорода в атмосфере является неизменной, поэтому этот фактор нельзя рассматривать как такой, который определяет различия между экосистемами или особенности их динамики. На меньшем пространственном уровне такой фактор как механический состав почв может быть константным на значительной протяженности и в этом смысле он будет только определять свойства почвы как среды обитания, но не сможет объяснить различия между сообществами в пределах указанной однородности.

Вариабельность экологических факторов в пространстве и времени может являться причиной их регулирующего влияния на экосистемы. Также факторы нейтральной природы влияют на экологические сообщества. На уровне популяций нейтральные факторы приобретают форму ограничителей дисперсии, а на уровне сообщества - это изменчивость видового состава сообщества и особенностей межвидовых взаимодействий.

Степень вариабельности экологических факторов является существенной их характеристикой. Отсутствие их вариабельности приводит к переходу из категории регулирующих в категорию определяющих. Однако регуляторное воздействие экологических факторов преломляется через свойства самих экологических систем (резистентности и сенситивности). В случае если экологическая система никак не реагирует на изменение экологических факторов, такая система является индифферентной по отношению к указанным факторам. В случае наличия регулирующего влияния факторов может иметь место резистентность, сенситивность и пропорциональность реакции экологической системы.

Окружающая среда разнообразна и для экологических систем регулирующее воздействие оказывает не один фактор, а их совокупность. Многие измеряемые параметры среды взаимно скоррелированы. Поэтому в качестве действующих факторов выступают плеяды факторов, выраженных через корелляционные комплексы показателей среды. Аналитически эти комплексы могут быть представлены как главные компоненты 
(или многомерные факторы). Эти синтетические переменные могут быть получены в результате анализа главных компонент (или смешанного анализа главных компонент для свойств среды представленных как континуальными, так и дискретными переменными). Роль главной компоненты в описании суммарной вариабельности совокупности исходных переменных отражает соответствующее собственное число. На основе собственных чисел можно оценить вклад главной компоненты в общую вариабельность признакового пространства, а также ранжировать переменные по убыванию их значимости.

Сообщество также варьирует, и для описания этого варьирования могут привлекаться экологические факторы. Аналитически эта процедура выполняется с помощью фракционирования вариации сообщества, что основывается на одной из техник ординации сообществ - анализе избыточности (Redundancy analysis - CA) (Borcard et al., 1992). Этот подход позволяет проверить гипотезу о достоверности влияния фактора на структуру экологического сообщества с помощью процедуры ANOVA, а также оценить объясненную фактором часть вариабельности сообщества. Эта оценка может быть сделана как в отношении общего уровня влияния фактора, так и с учетном вычленения действия фактора, обусловленного взаимодействием с другими факторами (так называемое условное влияние). Если в качестве факторов используются главные компоненты, то эти синтетические переменные взаимно ортогональны (независимы). Но это не значит, что независимым является их воздействие на сообщество. В случае взаимодействия факторов условная дисперсия будет отличаться от безусловной дисперсии сообщества, обусловленной этими факторами. Суммарная условная дисперсия указывает на то, какую роль играют исследованные факторы в варьировании сообщества. Если в сумме эту величину принять за $100 \%$, удельная часть укажет на относительный вклад фактора в общее влияние на сообщество. Отношение удельной роли фактора (главной компоненты) в вариабельности сообщества к вкладу главной компоненты в суммарную вариабельность признакового пространства позволит оценить резистентность, сенситивность и пропорциональность реакции экологической системы на действие фактоpa. Если это отношение $>1$, речь идет о сенситивности: уровень вариабельности сообщества выше, чем относительная роль экологического фактора в варьировании признакового пространства. Если $<1$ - речь идет о резистентности: уровень вариабельности сообщества ниже, чем относительная роль экологического фактора в варьировании признакового пространства. Если отношение равно $1(\approx 1)$, изменения в сообществе пропорциональны уровню варьирования главной компоненты в сравнении с другими компонентами.

Оценка сенситивности, резистентности или пропорциональности может быть выполнена и для пространственных переменных (PCNM-переменные) по аналогичной процедуре.

Сообщество мезопедобионтов. В почве исследуемого полигона при ручной разборке проб обнаружено 34 вида почвенных животных. Плотность почвенной мезофауны изученного полигона составляет $244,1 \pm 34,3$ экз./м² (табл. 1).

Таблица 1

Видовой состав и обилие почвенной мезофауны

\begin{tabular}{|c|c|c|c|}
\hline \multirow{3}{*}{ Таксоны } & \multicolumn{3}{|c|}{ Численность, экз./ $\mathrm{M}^{2}$} \\
\hline & \multirow{2}{*}{$\begin{array}{c}\text { Среднее } \pm \text { ст. } \\
\text { ошибка }\end{array}$} & \multicolumn{2}{|c|}{$\begin{array}{c}\text { Доверительный } \\
\text { интервал }^{1}\end{array}$} \\
\hline & & $-95 \%$ & $+95 \%$ \\
\hline 1 & 2 & 3 & 4 \\
\hline \multicolumn{4}{|l|}{ Тип Annelidae } \\
\hline \multicolumn{4}{|l|}{ Класс Arachnida } \\
\hline \multicolumn{4}{|l|}{ Отряд Haplotaxida } \\
\hline \multicolumn{4}{|l|}{ Семейство Lumbricidae } \\
\hline Aporrectodea caliginosa trapezoides (Duges, 1828) & $101,18 \pm 8,04$ & 86,80 & 117,94 \\
\hline Aporrectodea rosea rosea (Savigny, 1826) & $21,79 \pm 2,97$ & 16,30 & 27,89 \\
\hline Dendrobaena octaedra (Savigny, 1826) & $6,86 \pm 1,17$ & 4,72 & 9,30 \\
\hline \multicolumn{4}{|l|}{ Отряд Tubificida } \\
\hline Семейство Enchytraeidae & & & \\
\hline
\end{tabular}

\begin{tabular}{|c|c|c|c|}
\hline 1 & 2 & 3 & 4 \\
\hline $\begin{array}{l}\text { Enchytraeus sp. } \\
\text { Tип Arthropoda } \\
\text { Класс Arachnida } \\
\text { Отряд Araneae } \\
\text { Семейство Lycosidae }\end{array}$ & $3,20 \pm 0,74$ & 1,83 & 4,88 \\
\hline $\begin{array}{c}\text { Xerolycosa miniata (L. C. Koch, 1834) } \\
\text { Семейство Thomisidae }\end{array}$ & $3,05 \pm 0,61$ & 1,83 & 4,11 \\
\hline $\begin{array}{l}\text { Xysticus sp. } \\
\text { Семейство Gnaphosidae }\end{array}$ & $0,30 \pm 0,30$ & 0,00 & 0,91 \\
\hline $\begin{array}{l}\text { Gnaphosidea sp. } \\
\text { Класc Chilopoda } \\
\text { Отряд Geophilomorpha } \\
\text { Семейство Geophilidae }\end{array}$ & $0,15 \pm 0,15$ & 0,00 & 0,46 \\
\hline $\begin{array}{l}\text { Geophilus proximus C. L. Koch, } 1847 \\
\text { Семейство Lithobiidae }\end{array}$ & $18,44 \pm 2,74$ & 13,56 & 24,69 \\
\hline $\begin{array}{l}\text { Lithobius (Monotarsobius) curtipes C. L. Koch, } 1847 \\
\text { Класc Diplopoda } \\
\text { Отряд Julida } \\
\text { Семейство Julidae }\end{array}$ & $1,37 \pm 0,43$ & 0,61 & 2,29 \\
\hline $\begin{array}{l}\text { Megaphyllum sjaelandicum (Meinert, 1868) } \\
\text { Отряд Polydesmida } \\
\text { Семейство Paradoxosomatidae }\end{array}$ & $6,70 \pm 1,14$ & 4,57 & 9,14 \\
\hline $\begin{array}{l}\text { Polydesmus inconstans Latzel, } 1884 \\
\text { Класс Insecta } \\
\text { Oтряд Coleoptera } \\
\text { Семейство Carabidae }\end{array}$ & $1,98 \pm 0,52$ & 0,91 & 2,90 \\
\hline Carabidae sp. (larv.) & $1,37 \pm 0,43$ & 0,61 & 2,29 \\
\hline Harpalus affinis (Schrank, 1781) & $0,30 \pm 0,22$ & 0,00 & 0,76 \\
\hline Amara tibialis (Paykull, 1798) & $1,98 \pm 0,49$ & 1,07 & 2,90 \\
\hline Harpalus amplicollis Ménétriés, 1848 & $0,15 \pm 0,15$ & 0,00 & 0,46 \\
\hline $\begin{array}{r}\text { Pterostichus melanarius (Illiger, 1798) } \\
\text { Семейство Chrysomelidae }\end{array}$ & $0,30 \pm 0,21$ & 0,00 & 0,76 \\
\hline $\begin{array}{c}\text { Chrysolina fastuosa (Scopoli, 1763) (larv.) } \\
\text { Семейство Curculionidae }\end{array}$ & $0,76 \pm 0,34$ & 0,15 & 1,52 \\
\hline $\begin{array}{l}\text { Otiorhynchus ligustici (Linnaeus, 1758) (larv.) } \\
\text { Семейство Elateridae }\end{array}$ & $0,15 \pm 0,15$ & 0,00 & 0,46 \\
\hline Agrypnus murinus (Linnaeus 1758) (larv.) & $0,15 \pm 0,15$ & 0,00 & 0,46 \\
\hline Athous haemorrhoidalis (Fabricius, 1801) (larv.) & $5,33 \pm 0,83$ & 3,81 & 7,01 \\
\hline Prosternon tessellatum (Linnaeus, 1758) (larv.) & $4,72 \pm 0,82$ & 3,20 & 6,40 \\
\hline Agriotes lineatus (Linnaeus, 1767) (larv.) & $2,90 \pm 0,66$ & 1,68 & 4,27 \\
\hline $\begin{array}{c}\text { Cardiophorus rufipes (Goeze, 1777) (larv.) } \\
\text { Семейство Staphylinidae }\end{array}$ & $7,01 \pm 1,72$ & 3,96 & 10,82 \\
\hline $\begin{array}{c}\text { Platydracus fulvipes (Scopoli, 1763) (larv.) } \\
\text { Семейство Tenebrionidae }\end{array}$ & $0,61 \pm 0,30$ & 0,00 & 1,22 \\
\hline $\begin{array}{c}\text { Isomira murina (Linnaeus, 1758) (larv.) } \\
\text { Семейство Melolonthidae }\end{array}$ & $1,07 \pm 0,39$ & 0,30 & 1,83 \\
\hline Melolontha melolontha (Linnaeus, 1758) (larv.) & $17,98 \pm 2,12$ & 14,17 & 22,70 \\
\hline $\begin{array}{l}\text { Serica brunnea (Linnaeus, 1758) (larv.) } \\
\text { Orpяд Diptera } \\
\text { Семейство Therevidae }\end{array}$ & $2,13 \pm 0,53$ & 1,07 & 3,20 \\
\hline $\begin{array}{c}\text { Thereva nobilitata (Fabricius, 1775) (larv.) } \\
\text { Семейство Tabanidae }\end{array}$ & $2,44 \pm 0,65$ & 1,22 & 3,81 \\
\hline $\begin{array}{c}\text { Tabanus bromius Linnaeus, } 1758 \text { (larv.) } \\
\text { Семейство Tipulidae }\end{array}$ & $0,15 \pm 0,15$ & 0,00 & 0,46 \\
\hline $\begin{array}{l}\text { Tipula lunata Linnaeus, } 1758 \text { (larv.) } \\
\text { Oтряд Lepidoptera } \\
\text { Семейство Noctuidae }\end{array}$ & $4,11 \pm 0,94$ & 2,44 & 6,25 \\
\hline $\begin{array}{l}\text { Agrotis clavis (Hufnagel, 1766) (larv.) } \\
\text { Класc Malacostraca } \\
\text { Отряд Isopoda } \\
\text { Семейство Trachelipodidae }\end{array}$ & $14,78 \pm 1,55$ & 12,19 & 18,21 \\
\hline $\begin{array}{l}\text { Trachelipus rathkii (Brandt, 1833) } \\
\text { Tип Mollusca } \\
\text { Класс Gastropoda } \\
\text { Отряд Pulmonata } \\
\text { Семейство Cochlicopidae }\end{array}$ & $5,79 \pm 1,42$ & 3,50 & 8,99 \\
\hline $\begin{array}{c}\text { Cochlicopa lubrica (O. F. Muller, 1774) } \\
\text { Семейство Vitrinidae }\end{array}$ & $2,74 \pm 0,71$ & 1,37 & 4,11 \\
\hline Vitrina pellucida (O. F. Muller, 1774) & $2,13 \pm 0,57$ & 1,07 & 3,35 \\
\hline
\end{tabular}

Примечание: 1 - оценивание доверительных интервалов и ошибки среднего выполнено с помощью бутстреп-процедуры.

Доминируют дождевые черви, которые в среднем составили $53,2 \%$ от суммарной численности сообщества. Дождевые черви представлены тремя видами: подстилочным Dendrobaena octaedra и двумя собственно почвенными видами Aporrectodea trapezoides и Aporrectodea rosea. Численность собственно почвенных червей в 17,9 раза выше, чем подстилочных. Таксономически близки к дождевым червям Enchytraeidae, численность которых составляет 3,20 \pm 0,74 экз./м². Численность пау- 
ков составляет 1,4\% от суммарного обилия комплекса мезопедобионтов. Более обильна другая группа хищных беспозвоночных - Chilopoda. Они составляют $8,1 \%$ от суммарной численности сообщества. Эта группа представлена двумя видами: подстилочным Lithobius curtipes и собственно почвенным Geophilus proximus. Численность собственно почвенных губоногих многоножек в 13,5 раза больше, чем подстилочных.

Сапротрофные многоножки Diplopoda составляют 3,6\% от суммарной численности сообщества и представлены двумя видами: первичными разрушителями подстилки Megaphyllum sjaelandicum и вторичным разрушителем подстилки Polydesmus inconstans. Первичным разрушителем подстилки являются также мокрицы Trachelipus rathkii, моллюски Cochlicopa lubriса и Vitrina pellucida, а также личинки Tipulidae. Их численность в сообществе невелика.

Разнообразен комплекс насекомых, представленный 20 видами. Их численность - 28,0\% от суммарного обилия сообщества мезопедобионтов. Представители отрядов Coleoptera, Di- ptera и Lepidoptera в почве изучаемого полигона находятся на личиночной стадии. Четыре вида жужелиц встречены на имагинальной стадии. Среди всего сообщества почвенных животных личиночные стадии составляют 26,9\%. Личинки (ювенильные формы) обнаружены только среди насекомых, среди которых эта возрастная стадия составляет 96,0\%.

Параметры среды обитания почвенных животных представлены 65 переменными: 34 эдафических показателей и 31 показатель растительного покрова. Большое число переменных и их взаимная корреляция делает обоснованным проведение анализа главных компонент как процедуры снижения размерности признакового пространства. Полученные в результате анализа новые переменные (главные компоненты) являются ортогональными (статистически независимыми, табл. 2).

В результате анализа эдафических характеристик выделено 8 главных компонент, собственные числа которых превышают 1. Первые 8 главных компонент описывают $80,8 \%$ общей дисперсии признакового пространства.

\section{Таблица 2}

Описательные статистики и анализ главных компонент

эдафических показателей среды (представлены достоверные коэффициенты корреляции, Р <0,05)

\begin{tabular}{|c|c|c|c|c|c|c|c|c|c|}
\hline \multirow{2}{*}{\multicolumn{2}{|c|}{$\begin{array}{r}\text { Показатель } \\
\end{array}$}} & \multicolumn{8}{|c|}{ Главные компоненты } \\
\hline & & \multirow[t]{2}{*}{1} & \multirow[t]{2}{*}{2} & \multirow[t]{2}{*}{3} & \multirow[t]{2}{*}{4} & \multirow[t]{2}{*}{5} & \multirow[t]{2}{*}{6} & \multirow[t]{2}{*}{7} & \multirow[t]{2}{*}{8} \\
\hline Твердость почвы & & & & & & & & & \\
\hline $0-5 \mathrm{~cm}$ & $1,83 \pm 0,014$ & 0,21 & 0,24 & - & 0,79 & - & - & 0,21 & $-0,22$ \\
\hline $5-10 \mathrm{~cm}$ & $2,10 \pm 0,047$ & 0,45 & - & - & 0,27 & - & 0,19 & 0,68 & - \\
\hline $10-15 \mathrm{~cm}$ & $1,96 \pm 0,054$ & 0,27 & - & - & - & - & - & 0,84 & - \\
\hline $15-20 \mathrm{~cm}$ & $1,86 \pm 0,042$ & 0,45 & - & $-0,39$ & 0,20 & - & - & 0,33 & 0,27 \\
\hline $20-25 \mathrm{~cm}$ & $1,97 \pm 0,036$ & 0,73 & - & - & 0,43 & - & - & - & - \\
\hline $25-30 \mathrm{~cm}$ & $2,29 \pm 0,054$ & 0,91 & - & - & - & - & - & - & - \\
\hline $30-35 \mathrm{~cm}$ & $2,55 \pm 0,075$ & 0,91 & - & - & - & - & - & - & - \\
\hline $35-40 \mathrm{~cm}$ & $2,96 \pm 0,088$ & 0,92 & - & - & - & - & - & - & - \\
\hline $40-45 \mathrm{~cm}$ & $3,34 \pm 0,095$ & 0,82 & 0,21 & - & - & 0,26 & - & - & - \\
\hline $45-50 \mathrm{~cm}$ & $3,77 \pm 0,081$ & 0,83 & - & - & - & 0,31 & - & - & - \\
\hline $50-55 \mathrm{~cm}$ & $4,17 \pm 0,067$ & 0,74 & - & - & - & 0,47 & - & - & - \\
\hline $55-60 \mathrm{~cm}$ & $4,30 \pm 0,074$ & 0,63 & 0,25 & - & - & 0,55 & - & - & - \\
\hline $60-65 \mathrm{~cm}$ & $4,38 \pm 0,069$ & 0,56 & 0,23 & - & - & 0,66 & - & - & - \\
\hline $65-70 \mathrm{~cm}$ & $4,61 \pm 0,047$ & 0,52 & - & - & - & 0,69 & - & - & - \\
\hline $70-75 \mathrm{~cm}$ & $4,76 \pm 0,039$ & 0,34 & - & - & - & 0,84 & - & - & - \\
\hline $75-80 \mathrm{~cm}$ & $4,81 \pm 0,035$ & 0,21 & 0,20 & 0,26 & - & 0,82 & - & - & - \\
\hline $80-85 \mathrm{~cm}$ & $4,89 \pm 0,027$ & - & - & 0,33 & - & 0,78 & - & - & - \\
\hline $85-90 \mathrm{~cm}$ & $4,93 \pm 0,018$ & - & - & 0,66 & - & 0,57 & - & - & - \\
\hline $90-95 \mathrm{~cm}$ & $4,95 \pm 0,016$ & - & - & 0,86 & - & - & - & - & - \\
\hline $95-100 \mathrm{~cm}$ & $4,96 \pm 0,011$ & - & - & 0,82 & - & - & - & - & - \\
\hline \multicolumn{10}{|c|}{ Другие эдафические показатели } \\
\hline EC, дСм/м & $0,25 \pm 0,017$ & $-0,31$ & $-0,76$ & - & - & - & $-0,24$ & $-0,28$ & - \\
\hline Температура, ${ }^{\circ} \mathrm{C}$ & $12,26 \pm 0,065$ & 0,21 & 0,70 & - & - & - & - & 0,24 & 0,44 \\
\hline Влажность, \% & $30,94 \pm 1,049$ & - & $-0,80$ & - & $-0,30$ & - & - & - & - \\
\hline 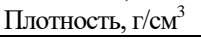 & $1,00 \pm 0,023$ & - & - & - & 0,91 & - & - & - & - \\
\hline \multicolumn{10}{|c|}{ Агрегатные фракции и корни растений, мм, \% } \\
\hline$>10$ & $23,54 \pm 1,066$ & $-0,24$ & $-0,78$ & - & - & - & $-0,45$ & - & - \\
\hline $7-10$ & $10,50 \pm 0,304$ & - & $-0,85$ & - & - & - & - & - & - \\
\hline $5-7$ & $11,44 \pm 0,286$ & - & $-0,67$ & - & - & - & 0,52 & - & 0,26 \\
\hline $3-5$ & $17,96 \pm 0,337$ & - & $-0,20$ & - & - & - & 0,83 & - & - \\
\hline $2-3$ & $13,46 \pm 0,297$ & - & 0,33 & $-0,32$ & - & 0,35 & 0,52 & - & $-0,25$ \\
\hline $1-2$ & $7,92 \pm 0,372$ & 0,26 & 0,70 & - & - & - & - & $-0,19$ & - \\
\hline $0,5-1,0$ & $1,69 \pm 0,082$ & - & 0,37 & - & - & - & - & - & 0,77 \\
\hline $0,25-0,50$ & $5,46 \pm 0,432$ & - & 0,89 & - & - & - & - & - & - \\
\hline$<0,25$ & $7,93 \pm 0,624$ & - & 0,92 & - & - & - & $-0,13$ & - & - \\
\hline Корни, \% & $0,11 \pm 0,013$ & 0,27 & 0,24 & - & - & - & 0,24 & $-0,69$ & - \\
\hline \% дисперсии & & 33,48 & 13,69 & 10,99 & 5,92 & 5,37 & 4,60 & 3,64 & 3,15 \\
\hline \% объясненной ди & & 0,28 & 3,12 & 0,96 & 0,60 & $-0,16$ & 0,74 & 2,38 & 1,15 \\
\hline $\mathrm{P}$ & & 0,187 & 0,001 & 0,027 & 0,048 & 0,646 & 0,033 & 0,001 & 0,012 \\
\hline $\begin{array}{l}\text { \% условной объяс } \\
\text { прочих главных к }\end{array}$ & сообщества с учетом & 0,78 & 0,40 & 1,14 & 0,61 & 0,03 & 0,37 & 3,05 & 0,67 \\
\hline Сенситивность/pe & цества & 0,33 & 0,41 & 1,47 & 1,46 & 0,07 & 1,15 & 11,90 & 3,03 \\
\hline
\end{tabular}

Примечания: “_“- отсутствие статистически достоверного коэффициента корреляции; ЕС - электрическая проводимость почвы.

Главную компоненту 1 можно содержательно интерпретировать как варьирование твердости почвы на глубине 0-80 см совместно с вариабельностью электропроводности и температуры почвы, а также некоторых агрегатных фракций. Главная компонента 2 в наибольшей степени чувствительна к вариабельности аг- регатного состава почвы. Главная компонента 3 отражает варьирование твердости на глубине 0-25 cм, а также влажности и плотности почвы. Главная компонента 5 отражает варьирование твердости почвы на глубине 40-90 см. Главная компонента 6 чувствительна к варьированию электропроводности почвы и некоторых 
агрегатных фракций. Главная компонента 7 чувствительна к варьированию твердости почвы на глубине 0-20 см, электропроводности и температуры почвы, а также к количеству корней в почве. Главная компонента 8 наиболее чувстительна к содержанию агрегатов размером 0,5-1 мм и температуры почвы.

Анализ характеристик растительности позволил установить 9 главных компонент, собственные числа которых превышают 1 (табл. 3). Они вместе описывают 79,0\% варьирования признакового пространства. Главные компоненты отражают сложный характер взаимосвязи между индикаторными показателями таким образом, что представляет некоторую сложность интерпретировать главные компоненты в терминах первичных экологических факторов. Главная компонента 1 отражает противоположную динамику проективного покрытия сильвантов и пратантов, что сопряжено с изменчивостью фитоиндикационных оценок широкого круга экологических факторов, преимущественно это режим освещенности, криоклимат и термоклимат. Главная компонента 2 чувствительна к варьированию режимов трофности и влажности (по
Бельгарду), кислотности освещенности (по Элленбергу) и кислотности, трофности и варьированию режима влажности (по Дидуху). Главная компонента 3 наиболее чувствительна к показателю влажности (по Дидуху). Главная компонента 4 чувствительна к роли в сообществе фанерофитов, что также объясняет связь этой компоненты с показателем освещенности по Дидуху. Главная компонента 5 отражает варьирование роли степантов в сообществе, а также показателя содержания карбонатов. Главная компонента 6 отражает режим азотного питания (как по Дидуху, так и по Элленбергу). Главная компонента 7 маркируется показателями трофности и омброклимата по Дидуху. Наибольшая корреляция с главной компонентой 8 характерна для шкалы континентальности по Дидуху. С этой компонентой также коррелирует шкала континентальности по Элленбергу, а также шкалы переменности увлажнения, кислотности, термоклимата по Дидуху и светового режима по Элленбергу. Шкала 9 отражает обратное соотношение в сообществе рудерантов и псаммофитов, что сопровождается вариабельностью кислотности и трофности эдафотопа.

\section{Таблица 3}

Описательные статистики и анализ главных компонент показателей растительности (представлены достоверные коэффициенты корреляции, $\mathrm{P}<0,05$ )

\begin{tabular}{|c|c|c|c|c|c|c|c|c|c|c|}
\hline \multirow{2}{*}{\multicolumn{2}{|c|}{ Показатели }} & \multicolumn{9}{|c|}{ Главные компоненты } \\
\hline & & 1 & 2 & 3 & 4 & 5 & 6 & 7 & 8 & 9 \\
\hline \multicolumn{11}{|c|}{ Фитоиндикационные шкалы Дидуха ${ }^{1}$} \\
\hline Hd & $11,72 \pm 0,193$ & - & - & $-0,90$ & - & - & - & - & - & - \\
\hline $\mathrm{fH}$ & $4,73 \pm 0,074$ & - & $-0,43$ & 0,44 & 0,26 & 0,21 & - & - & $-0,40$ & $-0,26$ \\
\hline Rc & $7,40 \pm 0,065$ & - & 0,50 & 0,41 & - & - & - & - & 0,41 & - \\
\hline $\mathrm{Sl}$ & $5,12 \pm 0,098$ & - & $-0,51$ & - & - & - & 0,22 & 0,54 & - & $-0,21$ \\
\hline $\mathrm{Ca}$ & $5,84 \pm 0,122$ & $-0,21$ & 0,26 & - & - & 0,73 & - & - & - & - \\
\hline $\mathrm{Nt}$ & $11,11 \pm 0,205$ & 0,43 & $-0,22$ & - & - & - & 0,64 & - & - & - \\
\hline Ae & $6,31 \pm 0,127$ & - & - & $-0,66$ & - & 0,20 & 0,26 & $-0,35$ & - & - \\
\hline $\operatorname{Tm}$ & $10,07 \pm 0,105$ & $-0,67$ & - & - & 0,23 & - & - & - & 0,35 & - \\
\hline Om & $13,15 \pm 0,140$ & - & $-0,33$ & - & - & 0,27 & - & 0,68 & - & - \\
\hline $\mathrm{Kn}$ & $7,66 \pm 0,084$ & - & 0,20 & $-0,19$ & - & $-0,20$ & - & - & $-0,79$ & - \\
\hline $\mathrm{Cr}$ & $9,15 \pm 0,089$ & $-0,80$ & - & $-0,23$ & - & - & $-0,30$ & - & - & - \\
\hline Lc & $5,93 \pm 0,132$ & $-0,33$ & - & - & 0,75 & - & - & - & - & - \\
\hline \multicolumn{11}{|c|}{ Индексы, основанные на экоморфах Бельгарда ${ }^{2}$} \\
\hline Troph_B & $2,27 \pm 0,017$ & - & $-0,78$ & 0,30 & - & $-0,20$ & - & - & - & - \\
\hline Hygr_B $\bar{B}$ & $3,34 \pm 0,034$ & $-0,35$ & 0,80 & $-0,25$ & - & - & - & $-0,28$ & - & - \\
\hline Hel_B & $3,01 \pm 0,017$ & $-0,83$ & 0,22 & - & - & - & - & $-0,22$ & - & - \\
\hline \multicolumn{11}{|c|}{ Фитоиндикационные шкалы Элленберга } \\
\hline Light Regime & $5,98 \pm 0,038$ & $-0,31$ & $-0,71$ & $-0,29$ & 0,22 & - & - & - & 0,29 & - \\
\hline Temperatures & $6,09 \pm 0,023$ & 0,21 & - & 0,73 & - & - & - & $-0,21$ & - & - \\
\hline Continentality of Climate & $5,23 \pm 0,019$ & - & $-0,63$ & - & - & - & - & 0,34 & 0,36 & - \\
\hline Humidity & $5,79 \pm 0,033$ & 0,49 & 0,24 & - & $-0,68$ & - & - & - & - & - \\
\hline Acidity & $6,23 \pm 0,030$ & $-0,46$ & 0,74 & - & - & - & 0,21 & - & - & - \\
\hline Nutrients Availability & $6,96 \pm 0,047$ & 0,27 & - & - & - & - & 0,88 & - & - & - \\
\hline \multicolumn{11}{|c|}{ Ценоморфы Бельгарда ${ }^{4}$, в долях от 1} \\
\hline$\overline{\mathrm{Pal}}$ & $0,03 \pm 0,003$ & - & - & $-0,71$ & 0,32 & - & - & - & - & - \\
\hline $\operatorname{Pr}$ & $0,09 \pm 0,013$ & $-0,92$ & - & - & - & - & - & - & - & - \\
\hline Ps & $0,09 \pm 0,013$ & - & - & 0,29 & 0,20 & - & - & - & - & 0,65 \\
\hline $\mathrm{Ru}$ & $0,012 \pm 0,001$ & - & $-0,30$ & - & - & - & - & - & - & $-0,71$ \\
\hline Sil & $0,87 \pm 0,014$ & 0,89 & - & - & $-0,26$ & - & - & - & - & - \\
\hline St & $0,004 \pm 0,001$ & - & $-0,20$ & - & - & 0,83 & - & - & - & - \\
\hline \multicolumn{11}{|c|}{ Жизненные формы Раункиера ${ }^{5}$ в долях от 1} \\
\hline$\overline{\mathrm{Ph}}$ & $0,39 \pm 0,014$ & 0,40 & $-0,40$ & 0,27 & $-0,71$ & - & - & - & - & - \\
\hline $\mathrm{nPh}$ & $0,16 \pm 0,008$ & - & 0,22 & $-0,38$ & - & - & - & $-0,69$ & - & - \\
\hline $\mathrm{HKr}$ & $0,26 \pm 0,011$ & - & - & $-0,45$ & 0,53 & - & $-0,42$ & 0,42 & - & - \\
\hline $\mathrm{T}$ & $0,16 \pm 0,009$ & - & 0,23 & 0,48 & 0,32 & - & 0,56 & $-0,27$ & - & - \\
\hline G & $0,03 \pm 0,009$ & $-0,92$ & - & - & - & - & - & - & - & - \\
\hline \multirow{2}{*}{\multicolumn{2}{|c|}{ \% объясненной дисперсии сообшества }} & 24,57 & 14,65 & 10,85 & 7,03 & 5,91 & 5,31 & 3,83 & 3,64 & 3,23 \\
\hline & & 0,85 & 0,52 & 0,68 & 0,85 & 4,38 & 0,17 & 0,78 & 0,02 & 0,20 \\
\hline \multicolumn{2}{|l|}{$\mathrm{P}$} & 0,02 & 0,05 & 0,03 & 0,02 & 0,00 & 0,18 & 0,02 & 0,32 & 0,16 \\
\hline \multicolumn{2}{|c|}{$\begin{array}{l}\text { \% условной объясненной дисперсии сообщества } \\
\text { с учетом прочих главных компонент }\end{array}$} & 1,01 & 0,66 & 0,82 & 1,01 & 4,79 & 0,28 & 0,93 & 0,12 & 0,31 \\
\hline \multicolumn{2}{|c|}{ Сенситивность / резистентность сообщества } & 0,41 & 0,45 & 0,76 & 1,45 & 8,17 & 0,53 & 2,45 & 0,32 & 0,96 \\
\hline
\end{tabular}

Примечание: “-“- - отсутствие статистически достоверного коэффициента корреляции; 1 - фитоиндикационные шкалы Дидуха: Нd - показатель гидроморф; $\mathrm{fH}$ - переменность увлажнения; $\mathrm{Rc}$ - режим кислотности; $\mathrm{Sl}$ - солевой режим; Сa - содержание карбонатных солей; $\mathrm{Nt}$ - содержание усвояемых форм азота; $\mathrm{Ae}$ - аэрация; Tm - масштаб радиационного баланса; Om - аридность-гумидность климата; Kn - континентальность климата; Cr - криорежим; Lc - шкала освещения; 2 - индексы, основанные на экоморфах Бельгарда: Troph_B - индекс трофности; Hygr_B - индекс влажности; Неl_B - индекс освещенности; 3 фитоиндикационные шкалы Элленберга: ценоморфы Бельгарда: Light Regime - L-шкала освещенности / затенения; Temperatures - T-шкала термоклимата; Continentality of Climate - K-шкала континентальности климата; Humidity - F-шкала увлажнения почв; Асіdity - R-шкала кислотности почв; Nutrients Availability - N-шкала богатства почв азотом; 4 - ценоморфы Бельгарда: Pal - палюданты; Pr - пратанты; Ps - псаммофиты; Ru - рудеранты; Sil - сильванты; $\mathrm{St}$ - степанты; 5 - жизненные формы Раункиера: $\mathrm{Ph}$ - фанерофиты; $\mathrm{nPh}$ - нанофанетрофиты; $\mathrm{HKr}$ - гемикриптофиты; T - террофиты; $\mathrm{G}$ - геофиты. 
Фракционирование варьирования сообщества. Анализ избыточности свидетельствует о том, что эдафические факторы среды, представленные с помощью главных компонент, описывают 9,7\% вариабельности сообщества мезопедобионтов. Процедура прямого выбора позволила установить, что статистически достоверное влияние на структуру сообщества оказывают главные компоненты 2, 3, 4, 6, 7 и 8. Эти главные компоненты описывают $6,4 \%$ вариабельности сообщества $(\mathrm{F}=$ $2,18, \mathrm{P}<0,001)$. Наибольшая условная объясненная дисперсия сообщества мезопедобионтов установлена для главной компоненты 7, несколько меньше этот показатель для компонент 3,4 и 8. Это определяет наибольшую сенситивность сообщества именно к этим главным компонентам варьирования эдафических переменных. Для главных компонент 1, 2, 5 реакцию сообщества можно охарактеризовать как резистентную, а для компоненты 6 - как пропорциональную.

С помощью анализа избыточности показано, что показатели свойств растительного, представленные в виде главных компонент, описывают 9,2\% вариабельности сообщества мезопедобионтов. Процедура прямого выбора позволила установить, что статистически достоверное влияние на структуру сообщества оказывают главные компоненты 1, 2, 3, 4, 5, 7. Они описывают 7,1\% вариабельности сообщества ( $\mathrm{F}=2,33, \mathrm{P}<$ $0,001)$. Наибольшей чувствительностью сообщество мезопедобионтов характеризуется по отношению к главной компоненте 5 , несколько меньше - к главным компонентам 4 и 7 . К главным компонентам 1, 2, 3, 6 и 8 сообщество резистентно, а к главной компоненте 9 - пропорционально.

Порядок главных компонент отражает их относительный вклад в варьирование признакового пространства показателей среды. Полученные результаты свидетельствуют о том, что вклад главных компонент в варьирование сообщества почвенных животных отличен от уровня варьирования самой главной компоненты. Эту особенность отражает чувствительность со-

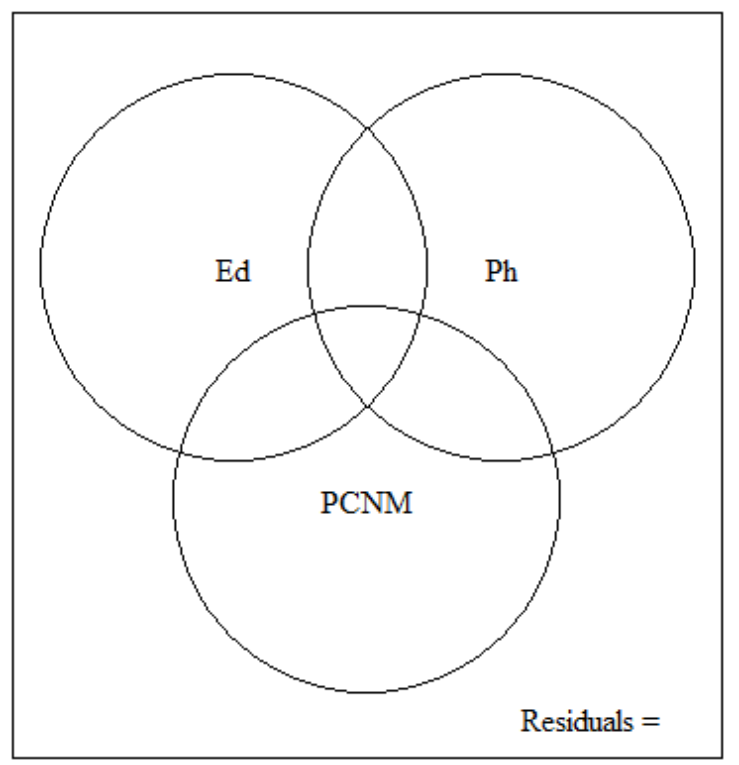

общества мезопедобионтов к действию главных компонент, оцененная как отношение уникального вклада главной компоненты в варьирование сообщества к описываемой компонентой дисперсии признакового пространства. По этому показателю сообщество мезопедобионтов среди эдафических характеристик наиболее чувствительно к главной компоненте 8 (чувствительность 3,56), а наименее - к главным компонентам 1, 2 и 4. Среди показателей растительного покрова наиболее существенное влияние на почвенных мезопедобионтов оказывают главные компоненты 4,6 и 7.

Выделено 72 пространственные переменные PCNM, которые вместе описывают $42,3 \%$ вариабельности сообщества мезопедобионтов. Процедура прямого выбора позволила выделить 33 пространственные переменные, которые описывают $36,5 \%$ вариабельности сообщества $(\mathrm{F}=2,81, \mathrm{P}<0,001)$.

Фракционирование вариации сообщества мезопедобионтов с учетом комбинации параметров среды и пространственных переменных показало, что факторы среды и пространственные переменные определяют $39,8 \%$ вариабельности сообщества $(\mathrm{F}=2,64, \mathrm{P}<0,001)$ (рис. 2). Почвенные факторы среды после выделения условного эффекта растительных факторов и пространственных переменных описывают $1,7 \%$ вариабельности сообщества $(\mathrm{F}=1,38, \mathrm{P}=0,014)$. Совместное влияние пространственных и эдафических факторов описывает $4,7 \%$ вариабельности сообщества мезопедобионтов. Растительные факторы среды после выделения условного эффекта эдафических факторов и пространственных переменных описывают $0,6 \%$ вариабельности сообщества, но это влияние не является статистически достоверным ( $\mathrm{F}=1,16, \mathrm{P}=0,18)$. Только пространственное структурирование растительных факторов является причиной их влияния на сообщество мезопедобионтов, что определяет $4,1 \%$ его вариабельности. Роль взаимодействия эдафических свойств и растительности крайне мало $(1,1 \%)$.

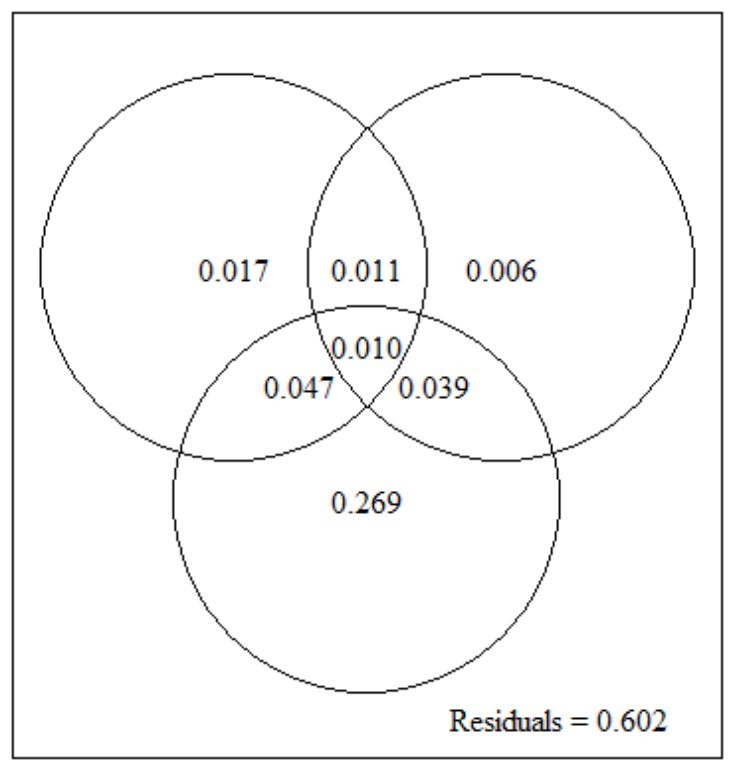

Рис. 2. Фракционирование вариации сообщества мезопедобионтов: слева - схема размещения факторов вариации, справа - оценки объясненной вариации (доли вариации от единицы); $\mathrm{Ed}$ - почвенные факторы среды; $\mathrm{Ph}$ - растительные факторы среды; PCNM - пространственные факторы

Пространственное и совместное средовое и пространственное влияние разделено на три компоненты: широкомасштабную, которая охватывает $30,1 \%$ потенциальной пространственной вариабельности (PCNM-переменные 2, 4, 5, 6, 7, 8, 9, 10, $11,12,13)$, среднемасштабную, которая охватывает $19,7 \%$ пространственной вариабельности (PCNM-переменные 17, 18, 20, $21,22,23,25,26,27,29,33)$ и детальномасштубную, которая охватывает 7,4\% потенциальной вариабельности (PCNM-переменные 34, 39, 48, 49, 52, 57, 59, 61, 63, 64, 69). Широкомасштабная компонента характеризуется периодичностью про- странственного варьирования с длиной волны 24,0-44,5 м, среднемасштабная -11,1-20,8 м, детальномасштабная -6,6-11,0 м.

Пространственное варьирование канонических осей, которые получены для различных по масштабности пространственных компонент варьирования сообщества почвенных животных, может быть представлено графически (рис. 3).

Широкомасштабная компонента пространственной изменчивости сообщества описывает $16,4 \%$ вариации $(\mathrm{F}=2,85, \mathrm{P}=$ $0,001)$, среднемасштабная компонента $-6,8 \%(\mathrm{~F}=1,68, \mathrm{P}=$ $0,002)$, детальномасштабная $-4,7 \%(\mathrm{~F}=1,46, \mathrm{P}=0,002)$ (табл. 4). 


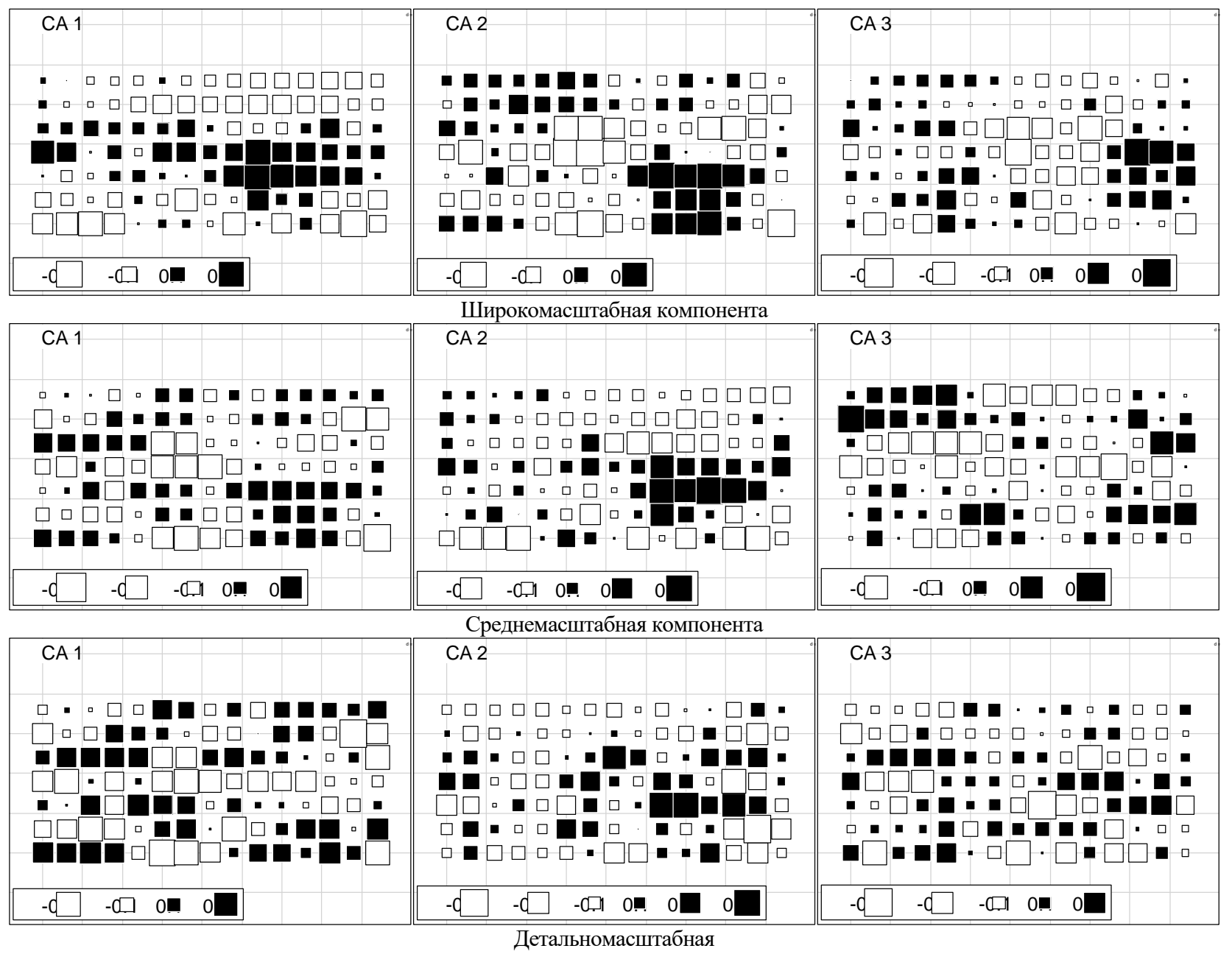

Рис. 3. Пространственное варьирование канонических осей, которые описывают различные масштабные уровни пространственной зависимости почвенной мезофауны: СA1-CA3 - канонические оси для широкомасштабной, среднемасштабной и детальномасштабной компонент; легенда для каждого рисунка обозначает варьирование осей в единицах среднеквадратического отклонения от минимального значения (самый большой белый квадрат) до наибольшего значения (самый большой черный квадрат)

Таблица 4

Характеристики пространственных компонент варьирования сообщества мезопедобионтов

\begin{tabular}{lccc}
\hline $\begin{array}{c}\text { Пространственные } \\
\text { компоненты }\end{array}$ & $\begin{array}{c}\text { Пространствен- } \\
\text { ная вариабель- } \\
\text { ность, \% }\end{array}$ & $\begin{array}{c}\text { Обьясненная } \\
\text { вариация } \\
\text { сообщества, \% }\end{array}$ & $\begin{array}{c}\text { Сенситивность / } \\
\text { резистентность } \\
\text { сообщества }\end{array}$ \\
\hline Широкомасштабная & 30,1 & 16,4 & 2,0 \\
Среднемасштабная & 19,7 & 6,8 & 1,2 \\
Детальномасштабная & 7,4 & 4,7 & 2,3 \\
\hline
\end{tabular}

Полученные результаты свидетельствуют о том, что наибольшей сенситивностью сообщество мезопедобионтов обладает по отношению к детальномасштабной пространственной компоненте, несмотря на относительно малую ее роль в формировании пространственных паттернов. Далее по важности следует широкомасштабная компонента и наименьшей сенси- тивностью сообщество характеризуется по отношению к среднемасштабной компоненте.

Маркерами осей являются 18 видов почвенных беспозвоночных (табл. 5). Среди них один вид маркирует шесть осей (A. clavis), два вида маркируют пять осей (A. rosea, A. haemorrhoidalis), пять видов маркируют четыре оси (A. trapezoides, C.rufipes, $D$. octaedra, M. melolontha, P. tessellatum), два вида маркируют три оси (C. lubrica, G. proximus), четыре вида маркируют две оси (P. inconstans, T. nobilitata, T. rathkii, V. pellusida) и четыре вида маркируют по одной оси (A. tibialis, Enchytraeus sp., L. curtipes, T. lunata).

Пространственные компоненты варьирования несут информацию как о пространственном, так и о средовом аспектах реагирования сообщества мезопедобионтов. Регрессионный анализ позволил выявить те главные компоненты, которые характеризуются статистически достоверными регрессионными коэффициентами (табл. 6).

Таблица 5

Виды с наибольшими показателями канонических осей по модулю

\begin{tabular}{|c|c|c|c|c|c|c|c|c|}
\hline \multicolumn{3}{|c|}{ Широкомасштабная компонента } & \multicolumn{3}{|c|}{ Среднемасштабная компонента } & \multicolumn{3}{|c|}{ Детальномасштабная компонента } \\
\hline CA 1 & CA2 & CA3 & CA1 1 & CA2 & CA3 & CA 1 & CA2 & CA3 \\
\hline \multicolumn{9}{|c|}{ Три вида с наибольшим значением канонических осей } \\
\hline $\begin{array}{l}\text { M. melolontha } \\
\text { C. rufipes } \\
\text { A. clavis }\end{array}$ & $\begin{array}{c}\text { C. rufipes } \\
\text { C. lubrica } \\
\text { V.pellusida }\end{array}$ & $\begin{array}{l}\text { M. melolontha } \\
\text { A. clavis } \\
\text { D. octaedra }\end{array}$ & $\begin{array}{l}\text { M. melolontha } \\
\text { G. proximus } \\
\text { A. clavis }\end{array}$ & $\begin{array}{l}\text { M. melolontha } \\
\text { C. rufipes } \\
\text { A. rosea }\end{array}$ & $\begin{array}{l}\text { D. octaedra } \\
\text { T. rathkii } \\
\text { G. proximus }\end{array}$ & $\begin{array}{c}\text { A. clavis } \\
\text { A. trapezoides } \\
\text { T. nobilitata }\end{array}$ & $\begin{array}{c}\text { A. haemorrhoidalis } \\
\text { V. pellusida } \\
\text { P. inconstans }\end{array}$ & $\begin{array}{l}\text { P. tessellatum } \\
\text { A. clavis } \\
\text { C. lubrica }\end{array}$ \\
\hline \multicolumn{9}{|c|}{ Три вида с наименьшим значением канонических осей } \\
\hline $\begin{array}{l}\text { Enchytraeus sp. } \\
\text { G. proximus } \\
\text { A. trapezoides }\end{array}$ & $\begin{array}{c}\text { A.tibialis } \\
\text { A. rosea } \\
\text { A. haemorrhoidalis }\end{array}$ & $\begin{array}{l}\text { A. haemorrhoidalis } \\
\text { T. nobilitata } \\
\text { C. rufipes }\end{array}$ & $\begin{array}{l}\text { P. tessellatum } \\
\text { A. haemorrhoidalis } \\
\text { A. rosea }\end{array}$ & $\begin{array}{l}\text { A. haemorrhoidalis } \\
\text { P. inconstans } \\
\text { A. trapezoides }\end{array}$ & $\begin{array}{c}\text { L. curtipes } \\
\text { A. clavis } \\
\text { P. tessellatum } \\
\end{array}$ & $\begin{array}{l}\text { C. lubrica } \\
\text { P. tessellatum } \\
\text { A. rosea } \\
\end{array}$ & $\begin{array}{c}\text { A. rosea } \\
\text { A. trapezoides } \\
\text { D. octaedra }\end{array}$ & $\begin{array}{l}\text { T. rathkii } \\
\text { D. octaedra } \\
\text { T. lunata }\end{array}$ \\
\hline
\end{tabular}




\section{Таблиша 6}

Результаты регрессионного анализа влияния параметров среды на пространственные компоненты варьирования сообщества мезопедобинтов (представлены статистически достоверные предикторы)

\begin{tabular}{|c|c|c|c|c|c|c|c|c|c|}
\hline \multirow{2}{*}{$\begin{array}{c}\text { Параметры } \\
\text { регрессионных моделей }\end{array}$} & \multicolumn{3}{|c|}{ Широкомасштабная компонента } & \multicolumn{3}{|c|}{ Среднемасштабная компонента } & \multicolumn{3}{|c|}{ Детальномасштабная компонента } \\
\hline & CA 1 & CA 2 & CA 3 & CA 1 & CA2 & CA3 & CA 1 & CA2 & CA 3 \\
\hline Эдафические главные компоненты & - & $1,3,7,8$ & 4,6 & 3,7 & - & 3,4 & 7 & 6 & - \\
\hline Растительные главные компоненты & $1,5,7$ & - & $1,3,5,6,7,8$ & 2 & 3,5 & 5 & - & 1,9 & - \\
\hline$R_{a}^{2}$ & 0,33 & 0,42 & 0,45 & 0,19 & 0,33 & 0,13 & 0,02 & 0,24 & 0,01 \\
\hline $\mathrm{P}$ & 0,00 & 0,00 & 0,01 & 0,003 & 0,00 & 0,023 & 0,47 & 0,00 & 0,73 \\
\hline
\end{tabular}

Примечания: “-“- отсутствие статистически достоверных предикторов; 1 - нумерация главных компонент и расшифровка см. табл. 2; 2 - см. табл. 3 ; СА1-СА3 - канонические оси см. рис. 2 и табл. 5.

Регрессионная модель влияния параметров среды на пространственные компоненты варьирования сообщества мезопедобионтов может объяснить $1-45 \%$ их изменчивости. При этом наибольшая роль средовых факторов характерна для широкомасштабной компоненты (33-45\%), несколько ниже эта роль для среднемасштабной компоненты (13-33\%) и наименьшая объяснительная способность регрессионной модели характерна для детальномасштабной компоненты ( $24 \%$ для статистически достоверной канонической оси). Статистическая значимость двух моделей для детальномасштабной выше критического уровня $(\mathrm{P}=0,05)$. Таким образом, детальномасштабные оси СА1 и СА2 в основном несут информацию о пространственном варьировании сообщества, которое имеет нейтральный характер.

\section{Обсуждение}

Почвенные экосистемы являются насыщенными видами, однако до сих пор остается неизвестной причина такого видового разнообразия (Wardle, 2006). Предполагается, что почвенные животные характеризуются низкой специализацией, что в большей степени характерно для прочих, менее разнообразных экосистем (Anderson, 1975; Maraun et al., 2003; Digel et al., 2014). Высокое разнообразие почвенных экосистем объясняется трехмерной природой почвенного тела и короткомасштабными градиентами ресурсов и условий, что позволяет обеспечить высокий уровень расхождения экологических ниш (Takeda, 1987; Berg and Bengtsson, 2007). Возможно также то, что в действительности животные имеют гораздо более различные трофические предпочтения, чем предполагалось ранее (Jorgensen et al., 2003; Schneider et al., 2004).

В результате исследования установлено, что плотность населения мезопедобионтов в дубраве в пойме р. Днепр составляет $244,1 \pm 34,3$ экз./ $\mathbf{m}^{2}$, а видовое богатство представлено 34 видами. Другое сообщество мезопедобионтов в пойме в аналогичном типе леса имело плотность населения $178,4 \pm$ 26,9 экз. $/ \mathrm{m}^{2}$, а видовое богатство представлено 34 видами (неопубликованные данные). Сравнение с биотопами в пределах арены р. Днепр свидетельствует о достаточно экстремальных условиях для почвенных животных в почвах поймы, так как видовое богатство и численность в данном биотопе находится на сравнительно низком уровне. Сбор данных по однотипной методике показал, что мезопедобионты широколиственного леса на арене р. Днепр представлены 45 видами с численностью 305,4 экз./ м $^{2}$ (Zhukov et al., 2015), луга - 47 видов с численностью 254,6 экз./ $\mathrm{M}^{2}$, болота - 59 видов с численностью 197,5 экз./м² (неопубликованные данные), в песчаной степи 29 видов с численностью 68,9 экз./ м $^{2}$ (Zhukov et al., 2016). Экстремальность местообитания проявляет себя в низком уровне численности и видового богатства сообщества, что является результатом действия лимитирующего (или нескольких) фактора. В соответствии с теорией экологической ниши (Hutchinson, 1957) именно лимитирующий характер действия фактора выполняет структурирующую роль в организации сообщества (Whittaker, 1960). Для выявления природы лимитирующих факторов нами изучены эдафические свойства и проведена синфитоиндикация экологических факторов в тех же пространственных точках, где отобраны пробы почвенных животных.
Общий список обнаруженных сосудистых растений в пределах изученного полигона составляет 60 видов $(8,7$ видов в одном сайте) (Zhukov et al., 2017). Tsatsenkin (1970) считает, что для надежной синфитоиндикации достаточно пяти видов растений в описании. Таким образом, видовое богатство растительного покрова характеризуется достаточным уровнем для того, чтобы использовать фитоиндикационное оценивание для описания пространственного варьирования эдафических и климатических свойств местообитания. Фитоиндикационные оценки интегрируют вариабельность режимов в профиле почвы на значительную глубину, которая определяется глубиной проникновения корневых систем растений. Кроме того, интеграция происходит в пределах площадки, где сделано каждое геоботаническое описание, так как ее размер значительно превосходит размеры почвенно-зоологической пробы. Размеры «точек» для сообщества почвенных животных $(0,25 \times 0,25$ м) и растительного сообщества $(3 \times 3$ м) различны. Следует также указать интеграцию динамики почвенных свойств во времени в фитоиндикационных оценках.

Трудоемкость проведения почвоведческих измерений вызывает определенные сложности для изучения их пространственного варьирования. Для решения этой задачи требуется значительный объем данных. Поэтому задача изучения пространственного варьирования почвенных свойств накладывает ограничение на возможный их перечень. С другой стороны, применение почвенных свойств как предикторов структуры почвенных сообществ накладывает ещё одно ограничение на почвенные данные: они должны быть экологически релевантными, т. е. отражать существенные свойства почвы как среды обитания.

Нами измерена твердость почвы в каждой точке отбора почвенно-зоологических проб на глубину 1 м. Также в каждой точке в поверхностном слое почвы измерены температура, влажность, плотность и фракционный состав. Проведенный анализ главных компонент свидетельствует о том, что как эдафические свойства, измеренные на глубину почвенного слоя, так и те, которые измерены только в поверхностном слое, характеризуются высокой степенью корреляции с общими главными компонентами. Это позволяет утверждать, что выбранная модель измерения эдафических показателей дает оценку варьирования свойств почвы как целого образования.

В результате анализа почвенных показателей выявлены 9 главных компонент, а анализа растительности - 7 главных компонент, собственные числа которых превышают 1 . Процедура анализа главных компонент позволяет решить несколько задач. Это снижение размерности признакового пространства, с помощью которого характеризуются экологические свойства среды. Также решается проблема мультиколинеарности - взаимной корреляции большинства эдафических свойств и свойств растительного покрова. Полученные главные компоненты являются ортогональными, то есть статистически независимыми, и в этом смысле полностью соответствуют требованиям для дальнейшего статистического анализа.

В отношении влияния на структуру сообщества роль факторов среды различна и не соотносится с их относительной вариабельностью, которая оценена с помощью анализа главных компонент. Процедура прямого выбора (forward selection - 
Blanchet et al., 2008) позволила установить, что из 8 эдафических главных компонент достоверными предикторами структуры сообщества почвенных животных являются 6, из 9 растительных - 6. Сообщество мезопедобионтов наиболее сенситивно к минорным главным компонентам, то есть к таким, которые характеризуются относительно малым собственным числом. Этот результат справедлив в отношении как эдафических показателей, так и показателей растительности. Среди эдафичсеких показателей главная компонента 7 , которая характеризует варьирование твердости почвы на глубине 0-20 см, электропроводность и влажность почвы, содержание агрегатов размером 1-2 мм и корни, описывает только 3,6\% варьирования признакового пространства, но играет ключевую роль в структурировании сообщества мезопедобионтов. Среди растительных показателей главная компонента 5 описывает $5,9 \%$ варьирования, но к ней сообщество мезопедобионтов наиболее сенситивно. Содержательный аспект этой компоненты достаточно «маргинален» по отношению к общей экологической обстановке в исследованном дубовом лесу: это проективное покрытие степантов в растительном сообществе и связанные с этим показателем изменения фитоиндикационных оценок. Для объяснения полученных результатов можно предположить, что характер основной вариабельности экологических условий в пределах изучаемой экосистемы близок к экологическому оптимуму видов, составляющих сообщество мезопедобионтов. Поэтому вариабельность экологических режимов не находит существенного отклика в структуре сообщества. Минорные факторы отражают сравнительно малые флуктуации свойств среды, но эти изменения существенно выходят за оптимальные рамки для почвенных животных данного сообщества.

Помимо факторов среды для описания структуры сообщества почвенных животных использовали пространственные переменные, или PCNM-переменные (Dray et al., 2006). Исходное число и свойства PCNM-переменных определяются взаимной конфигурацией в пространстве точек отбора проб. Наша модель отбора проб порождает 72 PCNM-переменных. Из этого числа с помощью процедуры прямого выбора производили селекцию тех, которые наилучшим образом описывают структуру сообщества. Таких переменных установлено 30. Пространственные PCNM-переменные описывают значительно больше вариации сообщества $(26,9 \%)$, чем эдафические факторы $(9,7 \%)$ и факторы растительности $(9,2 \%)$. При этом для факторов среды характерна значительная пространственная структурированность. Из 9,7\% вариабельности сообщества почвенных животных, обусловленных эдафическими факторами, к индивидуальной компоненте относится $1,7 \%$, а $8,0 \%$ описывается пространственно структурированными эдафическими факторами. Растительная компонента, которая оказывает влияние на сообщество мезопедобионтов, является пространственно структурированной. Для сообщества дождевых червей наблюдали несколько иную картину: $33,0 \%$ вариации сообщества описывали факторы среды и только 1,8\% - пространственная компонента (Jiménez et al., 2014). Авторы считают, что такой результат находится в соответствии с моделью Хатчинсона контроля сообщества факторами среды. Можно предположить, что изученное нами сообщество организовано в большей степени под воздействием факторов нейтральной природы. Однако пространственную компоненту варьирования в полной мере нельзя отождествлять с нейтральной компонентой структурирования сообщества. Включение в рассмотрение почвенных данных существенно снижало количество вариации структуры сообщества, объясненное пространством, таким образом снижая важность «нейтральной» компоненты (Baldeck et al., 2013; Chang et al., 2013).

Структура сообществ почвенных животных демонстрирует значительную вариабельность на микроуровне $(<1$ м). В формировании мозаичности принимают активное участие такие свойства почвы как структура порового пространства, почвенный микроклимат, структура корневых систем растений, стру- ктура наземного растительного покрова (Berg and Bengtsson, 2007; Berg, 2012; Viketoft, 2013). Почвенные организмы также характеризуются пространственными паттернами на мезоуровне (1-100 м) (Saetre, 1999; Ettema et al., 2000; Jimenez et al., 2006; Widenfalk et al., 2015). На этом уровне имеют значение такие свойства среды как градиенты почвенного $\mathrm{pH}$, влажности и состава растительного покрова (Ettema and Wardle, 2002; Berg, 2012).

Пространственная компонента варьирования сообщества фракционирована на три масштабные компоненты: детальномасштабную, среднемасштабную и широкомасштабную. В результате регрессионного анализа установлено, что объясненная дисперсия снижается от широкомасштабной компоненты к детальномасштабной. Межвидовые взаимодействия (конкуренция и хищничество), различия индивидуального участка и ограничения в расселении оказывают влияние на структуру сообщества почвенных животных на малых масштабных уровнях (Gonzalez, 2009; Martins da Silva et al., 2012). Можно предположить, что широкомасштабная компонента и, в меньшей степени, среднемасштабная компонента отражают варьирование пространственно структурированных факторов среды, тогда как детальномасштабная компонента в наибольшей степени может быть интерпретирована как отражающая нейтральный аспект структурирования сообщества. Такой же результат получен и при изучении мезофауны песчаной степи (Zhukov et al., 2016).

Для изученного сообщества макрофауны различные массштабные компоненты пространственного варьирования не отличаются существенно по степени их согласованности с факторами среды. Для канонических осей 1 и 3 широкомасштабной компоненты наибольшее значение имеют экологические факторы растительной природы, а для оси 2 - эдафические факторы. Среднемасштабную компоненту определяют в целом эдафические и растительные факторы. Каноническую ось 2 детальномасштабной компоненты определяют как растительные, так и эдафические факторы. Канонические оси 1 и 3 детальномасштабнойй компоненты можно рассматривать как маркеры нейтральных процессов.

\section{Заключение}

Причинами структурирования сообщества почвенной макрофауны являются эдафические, растительные и пространственные факторы. Роль этих факторов различна на детальномасштабном, среднемасштабном и широкомасштабном пространственных уровнях. Варьирование структуры сообщества под влиянием эдафических и растительных факторов можно отнести к категории детерминистского воздействия, которое осуществляется в рамках теории экологической ниши. Пространственную компоненту варьирования можно отнести к результатам действия факторов нейтральной природы. Однако пространственное варьирование растительного сообщества также подчиняется действию детерминистских и нейтральных факторов. Это проявляет себя в их пространственной структурированности. Аналогичную природу имеет и пространственное варьирование почвенных свойств. Почва как среда обитания испытывает структурирующее влияние растительного покрова, откуда возникают пространственные паттерны почвенных свойств.

Внешние средовые экологические факторы и внутренние, обусловленные межвидовыми взаимодействиями и имеющие нейтральную природу, вызывают специфические реакции сообщества на их воздействие. Эти особенности преломляются через различные аспекты устойчивости сообщества и могут быть описаны с помощью таких категорий как резистентность, сенситивность и пропорциональность. Предложенная процедура количественной оценки указанных свойств позволила установить, что макрофауна пойменной почвы обладает резистентностью к факторам среды, которые превалируют по уровню своего варьирования, тогда как к 
минорным факторам макрофауна высоко чувствительна. Также сообщество обитателей почвы характеризуется сенситивностью к детальномасштабному варьированию, которое, наиболее вероятно, имеет нейтральную природу.

\section{References}

Adler, P. B., Hillerislambers, J., \& Levine, J. M. (2007). A niche for neutrality. Ecology Letters, 10, 95-104.

Amarasekare, P. (2003). Competitive coexistence in spatially structured environments: A synthesis. Ecology Letters, 6, 1109-1122.

Anderson, J. M. (1975). The enigma of soil animal species diversity. In: Vanek, J. (Ed.). Progress in soil zoology. Academia, Prague. pp. 51-57.

Anderson, M. J. (2011). Navigating the multiple meanings of $\beta$-diversity: A roadmap for the practicing ecologist. Ecology Letters, 14, 19-28.

Baldeck, C. A., Harms, K. E., Yavitt, J. B., John, R., Turner, B. L., Valencia, R., Navarrete, H., Davies, S. J., Chuyong, G. B., Kenfack, D., Thomas, D. W., Madawala, S., Gunatilleke, N., Gunatilleke, S., Bunyavejchewin, S., Kiratiprayoon, S., Yaacob, A., Supardi, M. N., \& Dalling, J. W. (2013). Soil resources and topography shape local tree community structure in tropical forests. Proceedings of the Royal Society B, 280, 2012-2032.

Barot, S., \& Gignoux, J. (2004). Mechanisms promoting plant coexistence: Can all the proposed processes be reconciled? Oikos, 106, 185-192.

Belgard, A. L. (1971). Stepnoe lesovedenye [Steppe forestry]. Forest Industry, Moscow (in Russian).

Belgard, A. L. (1950). Lesnaja rastitel'nost' jugo-vostoka USSR [Forest vegetation of south-eastern part of Ukraine]. KGU im. Shevchenko Press, Kyiv (in Russian).

Brygadyrenko, V. V. (2015). Vplyv umov zvolozhennja ta mineralizacii gruntovogo rozchynu na strukturu pidstylkovoi’ mezofauny shyrokolystjanyh lisiv stepovoi' zony Ukrai'ny [Influence of moisture conditions and mineralization of soil solution on structure of litter macrofauna of the deciduous forests of Ukraine steppe zone]. Visnyk of Dnipropetrovsk University. Biology, Ecology, 23(1), 50-65 (in Ukrainian).

Brygadyrenko, V. V. (2016). Effect of canopy density on litter invertebrate community structure in pine forests. Ekológia (Bratislava), 35(1), 90-102.

Belyea, L. R., \& Lancaster, J. (1999). Assembly rules within a contingent ecology. Oikos, 86(3), 402-416.

Berg, M. P., \& Bengtsson, J. (2007). Temporal and spatial variability in soil food web structure. Oikos, 116, 1789-1804.

Blanchet, F. G., Bergeron, J. A. C., Spence, J. R., \& He, F. (2013). Landscape effects of disturbance, habitat heterogeneity and spatial autocorrelation for a ground beetle (Carabidae) assemblage in mature boreal forest. Ecography, 36, 636-647.

Blanchet, F. G., Legendre, P., \& Borcard, D. (2008). Forward selection of explanatory variables. Ecology, 89(9), 2623-2632.

Borcard, D., \& Legendre, P. (1994). Environmental control and spatial structure in ecological communities: An example using oribatid mites (Acari, Oribatei). Environmental and Ecological Statistics, 1, 37-61.

Borcard, D., Legendre, P., Avois-Jacquet, C., \& Tuosimoto, H. (2004). Dissecting the spatial structure of ecological data at multiple scales. Ecology, 85, 18261832.

Borcard, D., Legendre, P., \& Drapeau, P. (1992). Partialling out the spatial component of ecological variation. Ecology, 73, 1045-1055.

Burdon, F. J., Reyes, M., Alder, A. C., Joss, A., Ort, C., Räsänen, K., Jokela, J., Eggen, R. I., \& Stamm, C. (2016). Environmental context and magnitude of disturbance influence trait-mediated community responses to wastewater in streams. Ecology and Evolution, 6(12), 3923-3939.

Buzuk, G. N., \& Sozinov, O. V. (2009). Regressionnyy analiz v fitoindikatsii (na primere ekologicheskikh shkal D. N. Tsyganova) [Regression analysis in the bioindication (ecological scales D. N. Tsyganova as example)]. Botanika (issledovaniya). Institutt Eksperimental'noj Botaniki NAN Belarusi. Pravo i Ekonomika, Minsk, 37, 356-362 (in Russian).

Cadotte, M. W., \& Fukami, T. (2005). Dispersal, spatial scale and species diversity in a hierarchically structured experimental landscape. Ecology Letters, 8, 548-557.

Caruso, T., Taormina, M., \& Migliorini, M. (2012). Relative role of deterministic and stochastic determinants of soil animal community: A spatially explicit analysis of oribatid mites. Journal of Animal Ecology, 81(1), 214-221.

Chang, L., Zeleny, D., Li, C., Chiu, S., \& Hsieh, C. (2013). Better environmental data may reverse conclusions about niche- and dispersal-based processes in community assembly. Ecology, 94, 2145-2151.

Chase, J. M. (2003). Community assembly: When should history matter? Oecologia, 136, 489-498.

Chave, J. (2004). Neutral theory and community ecology. Ecology Letters, 7, 241-253.
Clark, J. S. (2012). The coherence problem with the unified neutral theory of biodiversity. Trends in Ecology and Evolution, 27, 199-203.

Decaëns, T., Jiménez, J. J., \& Rossi, J.-P. (2009). A null-model analysis of the spatio-temporal distribution of earthworm species assemblages in Colombian grasslands. Journal of Tropical Ecology, 25(4), 415-427.

Decaëns, T., \& Rossi, J.-P. (2001). Spatio-temporal structure of earthworm community and soil heterogeneity in a tropical pasture. Ecograpgy, 24(6), 671-682.

Diduh, Y. P. (2012). Prinzypy bioindicatzii [The principles of the bioindication]. Naukova Dumka, Kyiv (in Ukranian).

Didukh, Y. P., Fitsailo, T. V., Korotchenko, I. A., Yakushenko, D. M., \& Pashkevych, N. A. (2011). Biotopi lisovoi ta lisostepovoi zon Ukrainy [Biotopes of forest and forest-steppe zones of Ukraine]. LLC Macros, Kyiv (in Ukranian).

Didukh, Y. P. (2011). The ecological scales for the species of Ukrainian flora and their use in synphytoindication. Phytosociocentre, Kyiv.

Digel, C., Curtsdotter, A., Riede, J., Klarner, B., \& Brose, U. (2014). Unravelling the complex structure of forest soil food webs: Higher omnivory and more trophic levels. Oikos, 123, 1157-1172.

Donohue, I., Petchey, O. L., Montoya, J. M., Jackson, A. L., McNally, L., Viana, M., Healy, K., Lurgi, M., O’Connor, N. E., \& Emmerson, M. C. (2013). On the dimensionality of ecological stability. Ecology Letters, 16, 421-429.

Dornelas, M. (2010). Disturbance and change in biodiversity. Philosophical Transactions of the Royal Society B, 365, 3719-3727.

Drake, J. A. (1990). Communities as assembled structures: Do rules govern pattern? Trends in Ecology and Evolution, 5, 159-164.

Dray, S., Legendre, P., \& Peres-Neto, P. (2006). Spatial modelling: A comprehensive framework for principal coordinate analysis of neighbours matrices (PCNM). Ecological Modelling, 196, 483-493.

Ellenberg, H. (1974). Zeigerwerte der Gefässpflanzen Mitteleuropas. Scripta Geobotanica. Göttingen, 9, 197.

Ellwood, M. D., Manica, F. A., \& Foster, W. A. (2009). Stochastic and deterministic processes jointly structure tropical arthropod communities. Ecology Letters, 12, 277-284.

Ettema, C., \& Wardle, D. A. (2002). Spatial soil ecology. Trends in Ecology and Evolution, 17, 177-183.

Ettema, C. H., Rathbun, S. L., \& Coleman, D. C. (2000). On spatiotemporal patchiness and the coexistence offive species of Chronogaster (Nematoda: Chronogasteridae) in a riparian wetland. Oecologia, 125, 444-452.

Fukami, T. (2010). Community assembly dynamics in space. In: Verhoef, H. A., \& Morin, P. J. (Eds.). Community ecology: Processes, models, and applications. Oxford University Press, Oxford.

Gazol, A., \& Ibanez, R. (2010). Plant species composition in a temperate forest: Multi-scale patterns and determinants. Oecologia, 36, 634-644.

Gonzalez, A. (2009). Metacommunities: Spatial community ecology. Wiley, Hoboken, NJ.

Grimm, V., Schmidt, E., \& Wissel, C. (1992). On the application of stability concepts in ecology. Ecological Modelling, 63, 143-161.

Grimm, V., \& Wissel, C. (1997). Babel, or the ecological stability discussions: An inventory and analysis of terminology and a guide for avoiding confusion. Oecologia, 109, 323-334.

Hu, Y.-H., Sheng, D.-Y., Xiang, Y.-Z., Yang, Z.-J., Xu, D.-P., Zhang, N.-N., \& Shi, L.-L. (2013). The environment, not space, dominantly structures the landscape pattems of the richness and composition of the tropical understory vegetation. PLoS ONE, 8(11), e81308.

Hubbell, S. P. (2001). The unified neutral theory of biodiversity and biogeography. Princeton University Press, Princeton, New Jersey, USA.

Hutchinson, G. E. (1957). Concluding remarks. Cold Spring Harbour Symposium on Quantitative Biology, 22, 415-427.

Hutchinson, G. E. (1965). The niche: An abstractly inhabited hypervolume. The ecological theatre and the evolutionary play. Yale University Press, New Haven.

Ives, A. R. (1995). Measuring resilience in stochastic systems. Ecological Monographs, 65, 217-233.

Ives, A. R. (1999). Stability and variability in competitive communities. Science, 286(5439), 542-544.

Jiménez, J. J., Decaëns, T., Lavelle, P., \& Rossi, J.-P. (2014). Dissecting the multiscale spatial relationship of earthworm assemblages with soil environmental variability, BMC Ecology, 14-26.

Jiménez, J. J., Decaëns, T., \& Rossi, J.-P. (2012). Soil environmental heterogeneity allows spatial co-occurrence of competitor earthworm species in a gallery forest of the Colombian "Llanos". Oikos, 121, 915-926.

Jorgensen, H. B., Elmholt, S., \& Petersen, H. (2003). Collembolan dietary specialisation on soil grown fungi. Biology and Fertility of Soils, 39, 9-15.

Karpachevsky, L. O. (2005). Ecologicheskoe pochvovedenie [Ecological pedology]. Moscow, Geos (in Russian).

Kirby, K. N., \& Gerlanc, D. (2013). BootES: An R package for bootstrap confidence intervals on effect sizes. Behavior Research Methods, 45, 905-927.

Laliberte, A. S., Rango, A., Herrick, J. E., Fredrickson, E. L., \& Burkett, L. (2009). An object-based image analysis approach for determining fractional cover of 
senescent and green vegetation with digital plot photography. Joumal of Arid Environments, 69, 1-14.

Laliberte, E., Paquette, A., Legendre, P., \& Bouchard, A. (2009). Assessing the scale-specific importance of niches and other spatial processes on beta diversity: A case study from a temperate forest. Oecologia, 159, 377-388.

Lawton, J. (1999). Are there general laws in ecology? Oikos, 84, 177-192.

Legendre, P. (1993). Spatial autocorrelation: Trouble or new paradigm? Ecology, 74, 1659-1673.

Legendre, P., Borcard, D., \& Peres-Neto, P. R. (2005). Analyzing beta diversity: Partitioning the spatial variation of community composition data. Ecological Monographs, 75, 435-450.

Legendre, P., Mi, X., Ren, H., Ma, K., Yu, M., Sun, I.-F., \& He, F. (2009). Partitioning beta diversity in a subtropical broadleaved forest of China. Ecology, 90, 663-674.

Maraun, M., Martens, H., Migge, S., Theenhaus, A., \& Scheu, S. (2003). Adding to 'the enigma of soil animal diversity': Fungal feeders and saprophagous soil invertebrates prefer similar food substrates. European Joumal of Soil Biology, 39, 85-95

Martins da Silva, P., Berg, M. P., Serrano, A. R. M., Dubs, F., \& Sousa, J. P. (2012) Environmental factors at different spatial scales goveming soil fauna community pattems in fragmented forests. Landscape Ecology, 27, 1337-1349.

McArdle, B. H., \& Anderson, M. J. (2004). Variance heterogeneity, transformations and models of species abundance: A cautionary tale. Canadian Journal of Fisheries and Aquatic Sciences, 61, 1294-1302.

Murphy, S. J., Audino, L. D., Whitacre, J., Eck, J. L., Wenzel, J. W., Queenborough, S. A., \& Comita, L. S. (2015). Species associations structured by environment and land-use history promote beta-diversity in a temperate forest. Ecology, 96(3), 705-715.

Odum, E. (1953). Fundamentals of Ecology. Saunders, Philadelphia.

Pennisi, B. V., \& van Iersel, M. (2002). 3 ways to measure medium EC. GMPro, 22(1), 46-48.

Pimm, S. L. (1984). The complexity and stability of ecosystems. Nature, 307, 321-326.

Rossi, J. P. (2003). Clusters in earthworm spatial distribution. Pedobiologia, 47(5-6), 490-496.

Rossi, J.-R., Lavelle, P., \& Tondoh, J. E. (1996). Statistical tool for soil biology. XI. Autocorrelogram and Mantel test. European Journal of Soil Biology, 32, 195-203.

Saetre, P. (1999). Spatial patterns of ground vegetation, soil microbial biomass and activity in a mixed spruce-birch stand. Ecography, 22, 183-192.

Schneider, K., Migge, S., Norton, R. A., Scheu, S., Langel, R., Reineking, A., \& Maraun, M. (2004). Trophic niche differentiation in soil microarthropods (Oribatida, Acari): Evidence from stable isotope ratios (N-15/N-14). Soil Biology and Biochemistry, 36, 1769-1774.

Schoener, T. W. (1974). Resource partitioning in ecological communities. Science, 185(4145), 27-39.

Siefert, A., Ravenscroft, C., Weiser, M. D., \& Swenson, N. G. (2012). Functional beta-diversity patterns reveal deterministic community assembly processes in eastern North American trees. Global Ecology and Biogeography, 22(6), $682-691$.

Soinenen, J., Lennon, J. J., \& Hillebrand, H. (2007). A multivariate analysis of beta diversity across organisms and environments. Ecology, 88, 2830-2838.

Steiner, C. F., Long, Z. T., Krumins, J. A., \& Morin, P. J. (2005). Temporal stability of aquatic food webs: Partitioning the effects of species diversity, species composition and enrichment. Ecology Letters, 8, 819-828.

Takeda, H. (1987). Dynamics and maintenance of collembolan community structure in a forest soil system. Researches on Population Ecology, 29, 291-346.

Tarasov, V. V. (2012). Flora Dnipropetrovs'koi’ ta Zaporiz'koi’ oblastej. Sudynn roslyny. Biologo-ekologichna harakterystyka vydiv [Flora of Dnipropetrovsk and Zaporizhzhya regions. Vascular plants. Biologycal and ecological characteristics of the species]. Dnipropetrovsk University Press, Dnipropetrovsk (in Ukrainian).

Tilman, D., Reich, P. B., \& Knops, J. M. H. (2006). Biodiversity and ecosystem stability in a decade-long grassland experiment. Nature, 441, 629-632.
Tsatsenkin, I. A. (1970). Ekologicheskaya otsenka kormovykh ugodiy Karpat Balkan po rastitelnomu pokrovu [Ecological evaluation of the fodder lands of the Carpathians and the Balkans on vegetation]. Institute of Forages, Moscow (in Russian)

Vadunina, A. F., \& Korchagina, S. A. (1986). Metody issledovaniya fizicheskikh svoystv pochv [Methods for research of physical properties of the soil]. Agropromizdat, Moscow.

Viketoft, M. (2013). Determinants of small-scale spatial patterns: Importance of space, plants and abiotics for soil nematodes. Soil Biology and Biochemistry, 62, 92-98.

Wardle, D. A. (2006). The influence of biotic interactions on soil biodiversity. Ecology Letters, 9, 870-886.

Weslien, J., Djupström, L. B., Schroeder, M., \& Widenfalk, O. (2011). Long-term priority effects among insects and fungi colonizing decaying wood. Journal of Animal Ecology, 80, 1155-1162.

Whalen, J. K. (2004). Spatial and temporal distribution of earthworm patches in corn field, hayfield and forest systems of Southwestern Quebec, Canada. Applied Soil Ecology, 27(2), 143-151.

Whittaker, R. H. (1960). Vegetation of the siskiyou mountains, Oregon and California. Ecological Monographs, 30, 279-338.

Whittaker, R. H. (1972). Evolution and measurement of species diversity. Taxonomy, 21, 213-251.

Widenfalk, L. A., Bengtsson, J., Berggren, Å., Zwiggelaar, K., Spijkman, E., HuyerBrugman, F., \& Berg, M. P. (2015). Spatially structured environmentalfiltering of collembolan traits in late successional salt marsh vegetation. Oecologia, 179(2), 537-549.

Wilson, J. B., \& Habiba, G. (1995). Limitation to species coexistence: Evidence for competition from field observations, using a patch model. Journal of Vegetation Science, 6, 369-376.

Zhukov, A. V. (2015). Foromorfy v sisteme ekomorf pochvennykh zhivotnykh [Phoromorphs in ecomorphs system of soil animals]. The Journal of V. N. Karazin Kharkiv National University. Series: Biology, 25, 254-266 (in Russian).

Zhukov, A. V., Kunakh, O. N. \& Novikova, V. A. (2015). Ekomorficheskaya organizaciya soobshchestv mezopedobiontov dubnyaka so svezhim raznotrav'em na arene r. Dnepr [The ecomorphic organization of mesopedobionts community of oak forest with the fresh grass on arena of the Dnieper river] The Kharkov Entomological Society Gazette, 23(2), 39-53 (in Russian).

Zhukov, A. V., Shtirts, A. D., Zadorozhnaja, G. A. \& Kunah, O. N. (2013). Frakcionirovanie prostranstvennoj variacii soobshchestva pancirnyh kleshchej (Acari: Oribatida) v pochve sel'skohozyajstvennogo polya v usloviyah stepnoj zony Ukrainy [Fractionation of oribatid mites (Acari: Oribatida) community spatial structure in soil of agricultural field in Ukraine steppe zone]. Problems of Ecology and Environmental Protection of Technogenic Region, 1(13), 87-105 (in Russian)

Zhukov, A., \& Zadorozhnaya, G. (2016). Spatial heterogeneity of mechanical impedance of a typical chernozem: The ecological approach. Ekológia (Bratislava), 35, 263-278.

Zhukov, A. V. (2005). Bioraznoobrazie i ustojchivost' v prostranstve pochvennoj mezofauny [Biodiversity and spatial stability of soil mesofauna]. Ecology and Noospherology, 16(3-4), 165-177 (in Russian).

Zhukov, O. V., \& Gubanova, N. L. (2015). Riznomanittya ta dynamika uhrupovan' zemnovodnykh zaplavnykh ekosystem r. Samara-Dniprovs'ka [Diversity and dynamics of amphibians in floodplain ecosystems of the Samara river]. Visnyk of Dnipropetrovsk University. Biology, Ecology, 23(1), 66-73 (in Ukranian).

Zhukov, O. V., Kunah, O. M., Dubinina, Y. Y., \& Ganzha, D. S. (2017). Riznomanittya ta fitoindykatsiyni mozhlyvosti roslynnoho uhrupovannya [Diversity and phytoindication ability of plant community]. Ukrainian Journal of Ecology, 7(4), 81-99 (in Ukranian).

Zhukov, O. V., Kunah, O. N., \& Novikova, V. A. (2016). Funkcional’naya struktura soobshchestva mezopedobiontov dernovo-borovoj pochvy areny r. Dnepr [The functional organisation of the mesopedobionts community of sod pinewood soils on arena of the river Dnepr]. Visnyk of Dnipropetrovsk University. Biology, Ecology, 24(1), 26-39 (in Russian). 